\title{
Simulation of satellite water vapour lidar measurements: Performance assessment under real atmospheric conditions
}

\author{
Paolo Di Girolamo ${ }^{\mathrm{a}, *}$, Andreas Behrendt ${ }^{\mathrm{b}}$, Christoph Kiemle ${ }^{\mathrm{c}}$, Volker Wulfmeyer ${ }^{\mathrm{b}}$, \\ Heinz Bauer ${ }^{b}$, Donato Summa ${ }^{a}$, Andreas Dörnbrack ${ }^{c}$, Gerhard Ehret ${ }^{c}$ \\ a Dipartimento di Ingegneria e Fisica dell'Ambiente, Università degli Studi della Basilicata, 85100 Potenza, Italy \\ ${ }^{\mathrm{b}}$ Institut für Physik und Meteorologie, Universität Hohenheim, 70599 Stuttgart, Germany \\ ${ }^{c}$ Deutsches Zentrum für Luft-und Raumfahrt (DLR), Institute of Atmospheric Physics, Oberpfaffenhofen, 82230 Wessling, Germany
}

Received 2 February 2007; received in revised form 11 August 2007; accepted 12 August 2007

\begin{abstract}
A lidar simulator has been applied to assess the performances of a satellite water vapour differential absorption lidar (DIAL) system. Measurements performed by the airborne Deutsches Zentrum für Luft-und Raumfahrt (DLR) water vapour DIAL on 15 May 2002 during ESA's Water Vapour Lidar Experiment (WALEX), in combination with PSU/NCAR Mesoscale Model (MM5) output, were used to obtain backscatter and water vapour fields with high resolution and accuracy. These data and model output serve as input for the simulator, allowing for the performance of satellite DIAL under highly-inhomogeneous atmospheric conditions including clouds to be assessed. The airborne measurements show an intrusion of stratospheric air into the troposphere, and MM5 data used above the DLR Falcon airplane flight altitude are characterized by very high upper tropospheric humidity levels, comparable to those associated with strong mid-latitude transport events from the troposphere to the lowermost stratosphere. Results of the simulator reveal that the maximum systematic error does not exceed $5 \%$ up to $16 \mathrm{~km}$, except in the presence of thick cirrus and mid level clouds with an optical thickness up to 2 and, occasionally, inside the dry stratospheric intrusion, while the random error is less than $20 \%$ up to $16 \mathrm{~km}$ when spatial measurement resolutions are applied that follow the World Meteorological Organization (WMO) threshold observational requirements for numerical weather prediction (NWP). The bias is even smaller if a drier upper troposphere/lower stratosphere (UTLS) region from a reference atmosphere is considered. The results confirm the capability of satellite water vapour DIAL systems to retrieve thin structures of the tropospheric water vapour and particle backscatter fields, as well as its capability to provide low bias and random error measurements even in the presence of clouds.
\end{abstract}

(C) 2007 Elsevier Inc. All rights reserved.

Keywords: Differential absorption lidar; Space lidar; Water vapour remote sensing

\section{Introduction}

High-quality water vapour observations are necessary to improve our knowledge of the earth's climate system (Houghton et al., 2001), as well as to improve the skill of numerical weather forecasts (Crook, 1996; Weckwerth et al., 1999; Wulfmeyer et al., 2006). Atmospheric water vapour determines crucial processes like land-surface exchange, convection, cloud formation and evolution (Kärcher \& Haag, 2004), as well as initiation of precipitation (Tremberth et al., 2004), which are not thoroughly understood at present.

\footnotetext{
* Corresponding author.

E-mail address: digirolamo@unibas.it (P. Di Girolamo).
}

The high variability of atmospheric water vapour in both space and time (up to 4 orders of magnitude) represent a major challenge for its observation (Gérard et al., 2004). Currently, water vapour is observed mainly by the global radiosonde network and by satellite remote sensors. The global radiosonde network, though suffering from large data gaps and systematic errors which are primarily dependent on the type of humidity sensor (Ferrare et al., 2004; Soden \& Lanzante, 1996; Wang et al., 2002), still represents the main source of water vapour measurements for climate and weather research. Global coverage "in situ" measurements of atmospheric humidity are presently guaranteed by specially instrumented aircrafts as part of the MOZAIC programme (Marenco et al., 1998).

Passive remote sensing systems have been applied from space since the early seventies to get global coverage water vapour 
measurements. Both microwave and infrared remote sensing sounders have been considered. Among these, the Advanced VeryHigh Resolution Radiometer (AVHRR), the High-Resolution Infrared Radiation Sounder (HIRS), the Microwave Sounding unit (MSU) and the Advanced Microwave Sounding Unit (AMSU), flying on board the NOAA TIROS satellite series (e.g., Jedlovec, 1990), the Special Sensor Microwave Imager (SSM/I) onboard the DMSP polar orbiting satellites and NASA-NASDA Tropical Rainfall Measuring Mission (TRMM). It is nowadays well recognized that water vapour retrievals from space suffer from poor vertical and horizontal resolution, and do not reach the required level of accuracy needed for climate trend studies and have a limited impact on NWP through data assimilation (Bengtsson et al., 2004). Lidar systems based on the DIAL technique have been identified as potential candidate sensors to overcome these limitations.

The European Space Agency's Water Vapour Lidar Experiment in Space (WALES) mission (Ehret et al., 2001) was conceived in the frame of the Earth Observation Envelope Programme 2 for the purpose of providing high-quality water vapour profiles, globally and with good vertical resolution, using a DIAL system on a low Earth orbit satellite. WALES was finally not selected for the design phase (phase B) based primarily on cost estimates and because of development risks identified in the DIAL transmitter. More recently a satellite water vapour DIAL experiment similar to WALES, called SPACE WAVES, has been recommended for further technological studies in the context of the Earth Observation Envelope Programme 3.

The performances of satellite water vapour lidar systems have been simulated based on the application of sophisticated performance models by various groups (Ehret et al., 2001; Ismail \& Browell, 1989). Model simulations are routinely used to scale lidar systems and assess their expected performances. Performance models allow for determining the optimal specifications of the different lidar sub-systems in order to achieve specific observational requirements in terms of measurement uncertainty (random error/bias) and resolution (spatial/temporal). Model simulations are particularly necessary in case of airborne and satellite applications, where specific constraints between space and time resolution are present (Di Girolamo et al., 2006; Wulfmeyer et al., 2005).

In the frame of WALES assessment studies, instrument specifications were verified through the application of analytical models (Ehret et al., 2003). These models rely on analytical expressions for the random and systematic measurement errors (Fiorani \& Durieux, 2001; Ismail \& Browell, 1989; Wulfmeyer \& Walther, 2001a,b). However, while analytical models are in general a convenient and reliable tool to simulate DIAL system performances, several approximations are made which may not be valid for satellite systems. Among these, specific assumptions are made on error statistics and propagation. In addition, in analytical models the different sources of measurement bias are treated separately and the overall measurement bias is determined through the propagation of systematic errors. These limitations are overcome through the application of endto-end simulation models.

End-to-end simulators include a forward model for the generation of the synthetic lidar signals and a retrieval model for the application of the DIAL equation. Synthetic lidar signals are numerically generated based on the simulation of the different mechanisms of interaction of laser radiation with atmospheric constituents and of all devices present in the system setup. Retrievals from an ensemble of synthetic DIAL signals are then used to determine random and systematic errors based on the comparison of retrievals with input data.

An end-to-end model was developed in a joint effort between Università della Basilicata, University of Hohenheim and DLR. The model is described in detail in Di Girolamo et al. (2004).

This simulator is used in the present paper to estimate the performances of a satellite water vapour DIAL system in variable atmospheric conditions, as well as to determine the effects on system performances associated with atmospheric inhomogeneities and variable cloud scenes. The simulations are fed by measurements carried out by the DLR Falcon airplane water vapour DIAL system on 15 May 2002 during WALEX (Flentje et al., 2005). Two different outputs are generated by the end-to-end simulator: the $2 \mathrm{D}$ reconstruction of the particle backscatter and the water vapour mixing ratio fields as measured by the space-DIAL system, and the 2D-plot of random error and bias of water vapour measurements. These latter results are obtained by comparing the retrieved water vapour profiles with the input atmospheric measurements, which allow to assess systematic and noise errors in dependence of different atmospheric conditions. Results discussed in the paper demonstrate the potential of satellite DIALs to provide highly precise and accurate water vapour measurements with vertical and horizontal resolutions which satisfy WMO requirements for satellite observations (WMO, 1998).

The outline of this paper is the following. In Section 2.1-2.3, we briefly describe the measurement methodology and the system layout considered for the simulations and we summarize the procedure used to estimate random error and BIAS profiles from the synthetic DIAL signals. In Section 2.4, the WALEX dataset is introduced with a detail description of the procedure used to ingest the data into the simulator. In Section 2.5, the procedure to generate the synthetic DIAL signals is described. The main results of the simulations are outlined and discussed in Section 3 and summarized in Section 4.

\section{Simulations}

\subsection{DIAL methodology}

The DIAL technique has been employed for more than three decades in ground-based and air-borne applications for atmospheric water vapour profiling. The DIAL methodology has been described in detail in a variety of papers (e.g. Bösenberg, 1998; Ismail \& Browell, 1989; Wulfmeyer \& Walther 2001a,b). The DIAL technique is based on the detection of the elastic lidar echoes at two 
closely-spaced wavelengths, the on-line wavelength $\left(\lambda_{\text {on }}\right)$ falling on the centre of a water vapour absorption line and the off-line wavelength $\left(\lambda_{\text {off }}\right)$, falling on the line wing. If the backscatter signal is mainly determined by particles, the water vapour number density $n_{\mathrm{H}_{2} \mathrm{O}}(z)$ as a function of altitude $z$ is derived from the on-and off-line lidar signals through the so called Schotland approximation (1974):

$$
n_{\mathrm{H}_{2} \mathrm{O}}(z)=\frac{1}{2\left(\sigma_{\mathrm{on}}-\sigma_{\mathrm{off}}\right)\left(z_{2}-z_{1}\right)} \ln \frac{P_{\mathrm{off}}\left(z_{2}\right) P_{\mathrm{on}}\left(z_{1}\right)}{P_{\mathrm{on}}\left(z_{2}\right) P_{\mathrm{off}}\left(z_{1}\right)}
$$

with $\sigma_{\text {on/off }}$ being the water vapour absorption cross-section at the on/off-line wavelength, $P_{\text {on/off }}(z)$ being the backscatter signal at the on/off-line wavelength and $z_{1,2}$ being the lower/upper height of the scattering volume. Otherwise, Rayleigh Doppler broadening of the backscatter signal has to be considered, which results in a slightly more complex but still unique inversion (Ansmann, 1985). This procedure makes use of the aerosol backscattering information retrieved from the off-line return signal $P_{\text {off }}$ $(z)$. Assuming the laser profile to be a delta function, the water vapour profile accounting for the Rayleigh Doppler broadening correction term can be determined as:

$$
n_{\mathrm{H}_{2} \mathrm{O}}(z)=\frac{1}{2\left[\sigma_{\mathrm{on}}-\sigma_{\mathrm{off}}\right]\left(z_{2}-z_{1}\right)} \times\left\{\ln \frac{P_{\mathrm{off}}\left(z_{2}\right)}{P_{\mathrm{on}}\left(z_{2}\right)}-\ln \frac{P_{\mathrm{off}}\left(z_{1}\right)}{P_{\mathrm{on}}\left(z_{1}\right)}+D B\left(z_{2}\right)-D B\left(z_{1}\right)\right\}
$$

with:

$$
D B(z)=-\ln \left[\frac{\beta_{\mathrm{par}}(z)+\frac{\beta_{\mathrm{mol}}(z) \int_{0}^{\infty} b\left(v-v_{\mathrm{off}}, z\right) \tau_{W V}(v, z) d v}{\tau_{W V}\left(v_{\mathrm{off}}, z\right)}}{\beta_{\mathrm{par}}(z)+\frac{\beta_{\mathrm{mol}}(z) \int_{0}^{\infty} b\left(v-v_{\mathrm{on}}, z\right) \tau_{W V}(v, z) d v}{\tau_{W V}\left(v_{\mathrm{on}}, z\right)}}\right]
$$

where $b\left(v-v^{\prime}, R\right)$ is the Rayleigh backscatter line profile, and $\beta_{\text {mol }}(z)$ and $\beta_{\text {par }}(z)$ are the molecular and particle backscatter coefficient, respectively. The term $\tau_{\mathrm{WV}}(v, z)$ represents the attenuation of the laser beam throughout the sounded optical path from altitude $z_{0}$ to $z$ due to water vapour absorption, with:

$$
\tau_{W V}(v, z)=\exp -\int_{z_{0}}^{z} n_{\mathrm{H}_{2} \mathrm{O}}(z) \sigma(v, z) d z
$$

where $\sigma(v, z)$ is the absorption line shape represented by the Voigt profile.

While the DIAL technique refers to a minimum number of two laser wavelengths, more wavelengths are required to improve the dynamic range and precision of measurements. WALES and SPACE WAVES consider four different wavelengths, i.e. an off-line and three on-line wavelengths tuned on water vapour absorption lines of different strength (weak line $\lambda_{\text {wk }}$, medium line $\lambda_{\text {med }}$ and strong line $\lambda_{\text {str }}$ ). The quadruplet of signals $P_{\mathrm{off}}(z), P_{\mathrm{wk}}(z), P_{\mathrm{med}}(z)$ and $P_{\mathrm{str}}(z)$ form three distinct pairs. We consider the strategy of using, for each on-line wavelength, the measurement on the next weaker line as off-line measurement, this leading to three distinct wavelength pairs (i.e. $\lambda_{\text {str }}$ and $\lambda_{\text {med }}, \lambda_{\text {med }}$ and $\lambda_{\text {wk }}, \lambda_{\text {wk }}$ and $\left.\lambda_{\text {off }}\right)$. This cascading approach has to be preferred to the common off-line approach ( $\lambda_{\text {str }}$ and $\lambda_{\text {off }}, \lambda_{\text {med }}$ and $\lambda_{\text {off }}, \lambda_{\mathrm{wk}}$ and $\lambda_{\text {off }}$ ) because it benefits from the natural filtering effect for sky background provided by water vapour absorption (Ehret et al., 2001). In fact, sky background, which affects random error of measurements, is strongly reduced if off-line wavelengths are selected to fall on water vapour absorption lines, with absorption lines acting as natural filters to remove sky background entering the receiver.

In order to merge the information coming from the three different wavelength pairs in a single water vapour profile, it is necessary to perform a weighted mean of the three contributions. A first approximation estimate (Schotland approximation) of the water vapour profile is given by:

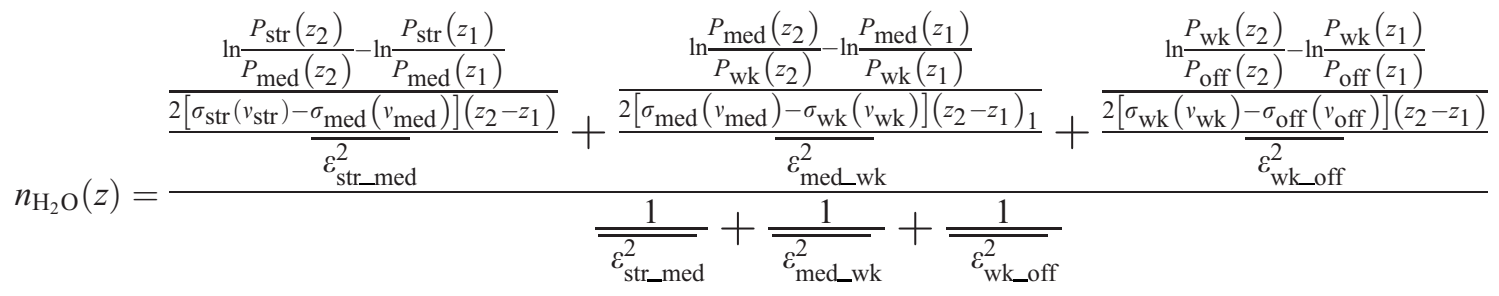


The weights used in the mean are obtained from the water vapour variances $\varepsilon_{\lambda}{ }^{2}$ of the three contributing profiles, which are estimated through the analytical equations defined by Wulfmeyer and Walther (2001a,b).

The first approximation water vapour profile determined through Eq. (5) can then be used to get a first approximation estimate of the Voigt profile $\sigma(v, z)$ and of the water vapour transmission profile $\tau_{W v}(v, z)$. Second approximation water vapour profiles for the three wavelength pairs are then obtained through Eq. (2), which are merged together to get a single water vapour profile through the weighted mean:

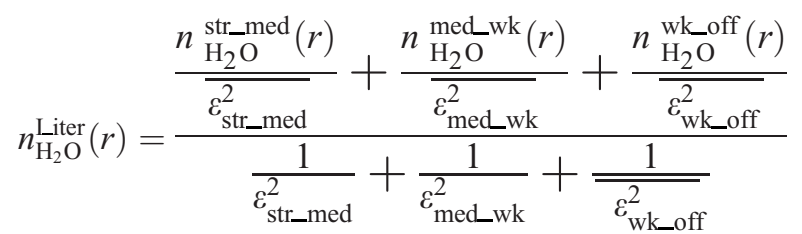

The procedure can be iterated 1-2 times to get the final water vapour profile. The DIAL retrieval algorithm is applied in the forward direction from the UTLS region $(20 \mathrm{~km})$ down to surface starting with the use of the strong signal pair $\left[P_{\text {str }}(z), P_{\text {med }}(z)\right]$. When signal-to-noise ratio of signals gets smaller than $\sim 5$ (this typically happening in the altitude region $9-11 \mathrm{~km}$ for the strong signal, in the altitude region $4-$ $6 \mathrm{~km}$ for the medium signal and in the altitude region $1-3 \mathrm{~km}$ for the weak signal), the information coming from the next weaker pair is considered in the merged water vapour profile (Di Girolamo et al., 2004). More details concerning the algorithms used are discussed in Di Girolamo et al. (2004).

\subsection{System specifications and orbit characteristics}

Two different system layouts were considered in the framework of the WALES feasibility studies which were the result of two independent technical studies carried out by separate industrial teams. Table 1 illustrates the main system specifications for the system layout which led to better performances based on the end-to-end simulations. The technical solutions considered to achieve these specifications are described in detail in Ehret et al. (2001).

The selection of the transmitted wavelengths and of the laser spectral requirements is very critical, because interference from absorption by other trace gases has to be avoided and temperature insensitive lines with optimal absorption coefficients have to be selected. In addition, good performance of both laser transmitter and detector at the selected wavelengths are required. Ehret et al. (2001) found four appropriate vacuum wavelengths at $\lambda_{\text {off }}=935.852 \mathrm{~nm}, \lambda_{\text {wk }}=935.906 \mathrm{~nm}, \lambda_{\text {med }}=935.561 \mathrm{~nm}, \lambda_{\mathrm{str}}=935.685 \mathrm{~nm}$. Wavelength selection was verified through dedicated sensitivity studies. Different clusters of absorption lines and off-line selections in the 925-940 $\mathrm{nm}$ region were considered with the goal of minimizing random error and bias in most atmospheric conditions (Di Girolamo et al., 2004).

Single-pulse energy is $72 \mathrm{~mJ}$ and pulse-repetition frequency is $25 \mathrm{~Hz}$ for each wavelength. Laser spectral requirements, verified through specific sensitivity studies, imply the use of a laser source with a line-width not exceeding $160 \mathrm{MHz}$, a frequency stability smaller than $60 \mathrm{MHz}$ and spectral purity better than 99.9\% (Di Girolamo et al., 2004; Ehret et al., 2001; Wulfmeyer et al., 2005).

Table 1

System baseline set of parameters

\begin{tabular}{|c|c|}
\hline Parameter & Value \\
\hline Laser wavelengths & $\begin{array}{l}\lambda_{\mathrm{str}}=935.685 \mathrm{~nm} \\
\lambda_{\mathrm{med}}=935.561 \mathrm{~nm} \\
\lambda_{\mathrm{wk}}=935.906 \mathrm{~nm} \\
\lambda_{\mathrm{off}}=935.852 \mathrm{~nm}\end{array}$ \\
\hline Laser ground footprint [FWHM] & $>29.1 \mathrm{~m}$ \\
\hline Laser repetition frequency & $25 \mathrm{~Hz}$ \\
\hline Laser pulse energy & $72 \mathrm{~mJ}$ \\
\hline Wavelength accuracy & $<60 \mathrm{MHz}$ \\
\hline Laser line-width & $<160 \mathrm{MHz}$ \\
\hline Laser spectral purity & $>99.9 \%$ (within $1 \mathrm{GHz}$ ) \\
\hline Telescope effective aperture area & $2.30 \mathrm{~m}^{2}$ \\
\hline Transmission FOV & $0.065 \mathrm{mrad}$ \\
\hline Reception FOV & $0.105 \mathrm{mrad}$ \\
\hline Alignment margin & $<13 \mu \mathrm{rad}$ \\
\hline Detector quantum efficiency: & 0.6 \\
\hline Detector gain & 50 \\
\hline Detector noise electrons readout (rms): & 28.7 \\
\hline Raw data vertical resolution & $50 \mathrm{~m}$ \\
\hline
\end{tabular}


Table 2

Threshold observational requirements for water vapour observation (altitude is intended above sea level)

\begin{tabular}{|c|c|c|c|c|}
\hline \multirow{2}{*}{$\frac{\text { Parameter }}{\text { Altitude range, km }}$} & \multicolumn{4}{|l|}{ Requirement } \\
\hline & 0-PBL top & PBL top-5 & $5-10$ & $10-16$ \\
\hline Vertical resolution, km & 1.0 & 1.0 & 1.5 & 2.0 \\
\hline Horizontal domain, $\mathrm{km}$ & & Global & & \\
\hline Horizontal integration, $\mathrm{km}$ & 25 & 100 & 150 & 200 \\
\hline Dynamic range, $\mathrm{g} / \mathrm{kg}$ & & $0.001-15$ & & \\
\hline Random error ( $1 \mathrm{~s}), \%$ & & 20 & & \\
\hline Bias, $\%$ & & $<3$ & & \\
\hline Lifetime, years & & $2-4$ & & \\
\hline Data reliability, \% & & 95 & & \\
\hline Timeliness, $\mathrm{h}$ & & $<3$ & & \\
\hline
\end{tabular}

The PBL top may vary sensitively as a function of time of the day, weather conditions and geographical region. We consider here an altitude level in the range $1.5-2.5 \mathrm{~km}$.

Simulations consider a sun synchronous low Earth orbit, with an orbiting height and speed of $450 \mathrm{~km}$ and $7 \mathrm{~km} / \mathrm{s}$, respectively. A dawn dusk orbit characterized by an ascending node crossing time of $6 \mathrm{~h}$ was selected. Simulations reported in the present paper refer to the vertical and horizontal resolutions in Table 2, which are considered to verify the achievement of the random error and bias requirements in this same table.

\subsection{Procedure to estimate the vertical profiles of random error and bias}

The procedure to estimate the random and systematic errors affecting water vapour measurements has been discussed in detail in Di Girolamo et al. (2004) and is briefly recalled in this section. This procedure implies the simulation of a large number of synthetic signals and the application to these signals of the retrieval procedure (namely the application of the DIAL equation). Specifically, $N$ retrievals of the water vapour profile $\left(n_{\mathrm{H}_{2} \mathrm{O}, i}^{\text {out }}(z)\right)$ can be determined from an ensemble of $N$ synthetic signals. The mean water vapour retrieval profile $\overline{n_{\mathrm{H}_{2} \mathrm{O}}^{\text {output }}}(z)$ in dependence of height $z$ is obtained as:

$$
\frac{\sum_{i=1}^{N} n_{\mathrm{H}_{2} \mathrm{O}, i}^{\text {output }}(z)}{N}(z)=\frac{\text { output }}{N}
$$

The systematic error (or relative bias, hereafter simply called bias) profile is then determined as the relative deviation of the mean retrieval profile from the input water vapour profile, based on the expression:

$$
\operatorname{BIAS}(\mathrm{z})=\frac{\overline{n_{\mathrm{H}_{2} \mathrm{O}}^{\text {output }}}(z)-n_{\mathrm{H}_{2} \mathrm{O}}^{\text {input }}(z)}{n_{\mathrm{H}_{2} \mathrm{O}}^{\text {input }}(z)}
$$

with $n_{\mathrm{H}_{2} \mathrm{O}}{ }^{\text {input }}(z)$ being the input water vapour profile.

The random error profile can then be determined as the root mean square $(R M S)$ deviation of single retrievals $n_{\mathrm{H}_{2} \mathrm{O}, i}^{\text {out }}(z)$ from the mean water vapour retrieval:

$$
\operatorname{RMS}(z)=\sqrt{\frac{\sum_{i=1}^{N}\left(n_{\mathrm{H}_{2} \mathrm{O}, i}^{\text {outut }}(z)-\overline{n_{\mathrm{H}_{2} \mathrm{O}}^{\text {output }}}(z)\right)^{2}}{N}}
$$

BIAS is contaminated from random error by an amount equal to approximately $N^{-0.5}$. As for $N=1000$ the estimates of BIAS are almost "noise-free" (residual error not exceeding 1\%), $N$ was taken equal to 1000 for all performance simulations discussed in this paper.

At any given altitude $z$ it is possible to define the probability distribution function of the simulated measurements based on the $N$ retrievals of the water vapour profile $n_{\mathrm{H}_{2} \mathrm{O}, i}^{\text {out }}(z)$; the distribution centre represents the BIAS at that given height, while the distribution width represents the measurement random error.

Performances to be achieved by satellite remote sensors in order to satisfy the World Meteorological Organization (WMO) threshold observational requirements for numerical weather prediction and climate research applications have been illustrated and discussed in several publications (Ehret et al., 2001; Gérard et al., 2004; Wulfmeyer et al., 2005) and are summarized in Table 2. These imply low bias $(<3 \%)$ and random error $(<20 \%)$ measurements of water vapour mixing ratio in the dynamic range $0.001-15 \mathrm{~g} / \mathrm{kg}$. 
Height-dependent horizontal and vertical resolutions are required, with higher resolutions in the planetary boundary layer (PBL) and lower troposphere, where humidity shows higher variability. The PBL height changes as a function of the geographical region (sea or land, orography) and weather conditions, and has a well defined diurnal variability. In high-pressure land areas, a mixed layer is present during the day, while a stable boundary layer with an overlaying residual layer is usually found at night, when convective activity is suppressed. An altitude level of the PBL top in the range $1.5-2.5 \mathrm{~km}$ can be considered in Table 2.

Horizontal and vertical averaging of the signals is required in order to reduce signal statistical fluctuations. Horizontal and vertical averaging windows must be compatible with the considered horizontal and vertical resolutions. The horizontal integration of the measurement $\Delta h$ is related to the integration time $\Delta t$ through the expression $\Delta h=v_{\mathrm{s}} \Delta t$, with $v_{\mathrm{s}}$ being the satellite speed at ground. Considering a satellite speed at ground of $7 \mathrm{~km} / \mathrm{s}$ and a laser pulse repetition frequency of $25 \mathrm{~Hz}$, the number of laser shots which need to be averaged per wavelength in order to get a ground track resolution of $25,100,150$ and $200 \mathrm{~km}$, is $89,357,536,714$, respectively. Four quadruplets of synthetic lidar signals $\left(P_{\lambda}{ }^{25 \mathrm{~km}}(z), P_{\lambda}{ }^{100 \mathrm{~km}}(z), P_{\lambda}{ }^{150 \mathrm{~km}}(z)\right.$ and $\left.P_{\lambda}{ }^{200 \mathrm{~km}}(z)\right)$ are generated and the algorithms above are separately applied to the four distinct quadruplets of signals. The overall bias and random error profiles are obtained by merging the separate bias and random error profiles obtained from each quadruplet of signals, namely $P_{\lambda}{ }^{25 \mathrm{~km}}(z)$ in the planetary boundary layer $(0-1.5 / 2.5 \mathrm{~km}), P_{\lambda}{ }^{100 \mathrm{~km}}(z)$ in the lower free troposphere $(1.5 / 2.5-5 \mathrm{~km}), P_{\lambda}{ }^{150 \mathrm{~km}}(z)$ in the upper free troposphere $(5-10 \mathrm{~km})$ and $P_{\lambda}{ }^{200 \mathrm{~km}}(z)$ in the UTLS $(10-16 \mathrm{~km})$. Using aerosols as atmospheric tracers, the PBL top is determined from the off-line signal as the first minimum of the range-corrected signal derivative (Hayden et al., 1997).

\subsection{Real atmospheric data: DLR Falcon water vapour DIAL measurements during WALEX}

WALEX was part of the DLR DIAL involvement in the International $\mathrm{H}_{2} \mathrm{O}$ Project (IHOP 2002, Southern Great Plains, MayJune 2002, Weckwerth et al., 2004). The DLR DIAL has been described in several papers (e.g., Poberaj et al., 2002). It is an allsolid-state DIAL system for tropospheric and lower stratospheric water vapour measurements flying onboard DLR's meteorological research aircraft Falcon 20. Its transmitter is based on an injection-seeded potassium titanyl phosphate (KTP) optical parametric oscillator (OPO) pumped by the second harmonic of a Q-switched, diode-pumped single-mode Nd:YAG laser operating at a repetition rate of $100 \mathrm{~Hz}$. In inter-comparison studies with other airborne and ground-based water vapour lidars and with radiosondes (Behrendt, Wulfmeyer, Di Girolamo et al., 2007; Behrendt, Wulfmeyer, Kiemle, et al., 2007), a relative bias smaller than 5\% was found for the DLR-DIAL data during IHOP_2002, which confirms the high quality of the DLR-DIAL measurements.

WALEX consisted of a round-trip flight from Germany to Oklahoma (US). The outbound journey took place in mid May and included several flight segments across the northern Atlantic Ocean, via Iceland, Greenland, and Goose Bay. The return journey in mid June 2002 was across the middle Atlantic Ocean, back via Maine, the Azores Islands, and Spain (Flentje et al., 2005). The roundtrip journey comprised a total of 24.5 flight hours, with 7 stopovers and approximately $8 \mathrm{~h}$ of ascent or descent periods. A total of about $15 \mathrm{~h}$ of lidar data have been collected. As a result of the intense dynamical activity over the Atlantic, a variety of complex atmospheric structures were observed during the flights. Among others: stratospheric intrusions, potential vorticity (PV) streamers, frontal zones, gravity waves, convection and patches of vertical turbulence. An interesting atmospheric scene to be ingested into the end-to-end simulator was found during a 1330-km flight segment between Ottawa (45N, 76W) and Springfield, Illinois (40N, 90W) on 15 May 2002. Flight altitude was $10 \mathrm{~km}$. Measurements are based on 10-s time averaging, corresponding to $2.33 \mathrm{~km}$ mean horizontal grid distance. The vertical resolution is $200 \mathrm{~m}$ at bottom, $500 \mathrm{~m}$ at top. Fig. 1 shows the time-height map of the water vapour mixing ratio as measured by DLR-DIAL along the 1330-km flight leg consisting of 570 individual profiles, while Fig. 2 shows the corresponding particle backscatter coefficient map. Approximately $200 \mathrm{~km}$ of data were affected by detector overloading. These data were removed from the measurement segment in correspondence with the final portion of the measurement record (profiles 476-570).

The period of the westbound ferry flights (13-15 May 2002) was characterized by a rapid cyclogenesis over the northeast of the United States (around $80^{\circ} \mathrm{W}, 45^{\circ} \mathrm{N}$ ) and above the Atlantic Ocean (Flentje et al., 2005). A mature extra-tropical cyclone with its centre near Montreal was slowly propagating north-eastward. The flight leg cut through the tropopause fold associated with the jet stream and the surface front, through the cold Arctic air at the back of the cyclone, and finally through the high-pressure system to the south. The associated water vapour distribution was characterized by a sequence of dry stratospheric intrusions. The main intrusion was about 1 to $2 \mathrm{~km}$ thick, extended horizontally a few hundreds kilometers and extended down to $\sim 500 \mathrm{~m}$ ASL (Fig. 1). This specific atmospheric scenario was selected because of the highly heterogeneous atmospheric conditions, which permitted us to verify system performances over a highly variable range of water vapour mixing ratios.

In order to simulate the synthetic lidar signals of a satellite DIAL system, information on atmospheric pressure, temperature and water vapour throughout the atmosphere is needed. Temperature and pressure profiles below $10 \mathrm{~km}$ are provided by the nearest available radiosonde. Above $10 \mathrm{~km}$, pressure, temperature and water vapour information was completed with mesoscale numerical simulation results. All the numerical simulations were performed with the NCAR/PSU mesoscale weather prediction model MM5. The non-hydrostatic compressible model is used in its version V3.4.0 (Dudhia, 1993; Dudhia et al., 2001). The upper boundary is set 


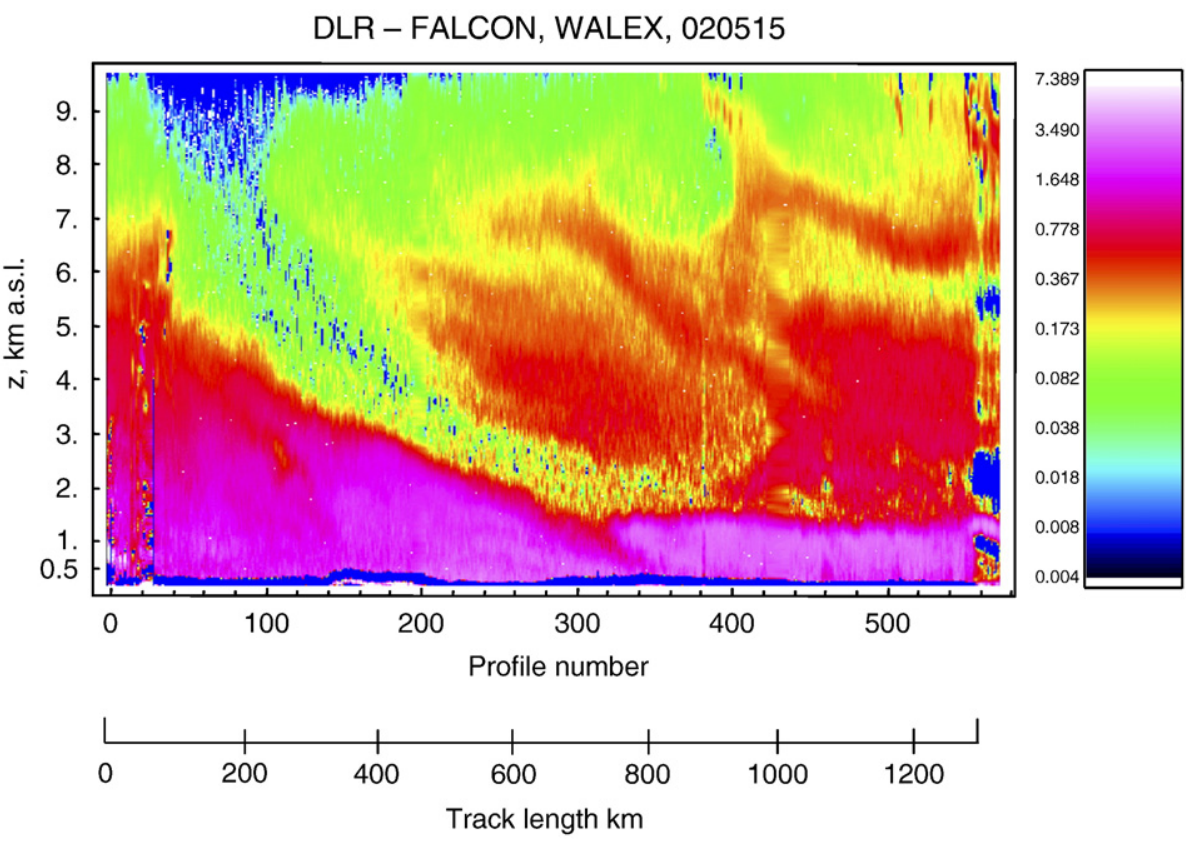

Fig. 1. Water vapour mixing ratio $(\mathrm{g} / \mathrm{kg})$ as measured by DLR-DIAL on 15 May 2002 during the WALEX experiment.

to $10 \mathrm{hPa}$, altogether 115 vertical levels are used (i.e. $\Delta z \sim 250 \mathrm{~m}$ ). The horizontal grid size is $\Delta x=36 \mathrm{~km}$ and for the current simulation a local grid refinement scheme with $\Delta x=12 \mathrm{~km}$ has been applied (Flentje et al., 2005).

A composite 2D cross-section of the water vapour field is obtained by merging water vapour information from DLR-DIAL and mesoscale simulation results. A very humid layer is present just above $10 \mathrm{~km}$ in the mesoscale simulation, leading to a large gradient in the humidity field in the transition region from DLR-DIAL to simulation results. The high water vapour contents in the MM5 dataset result from constraining relative humidity to be always larger than $10 \%$. This has been done in order to reproduce the very humid UTLS conditions which are reported to be generated by severe mid-latitude transport events from the troposphere to the lowermost stratosphere, for example in association with warm conveyor belts (Stohl, 2001; Wernli \& Bourqui, 2002). This atmospheric scene has to be considered as a worst case study for the assessment of system performances, which are representative for an extremely humid UTLS region. However, MM5 mixing ratios in 10-13 km region are largely exceeding real values also for very humid upper tropospheric conditions. In order to obtain a more realistic conjunction between DLR-

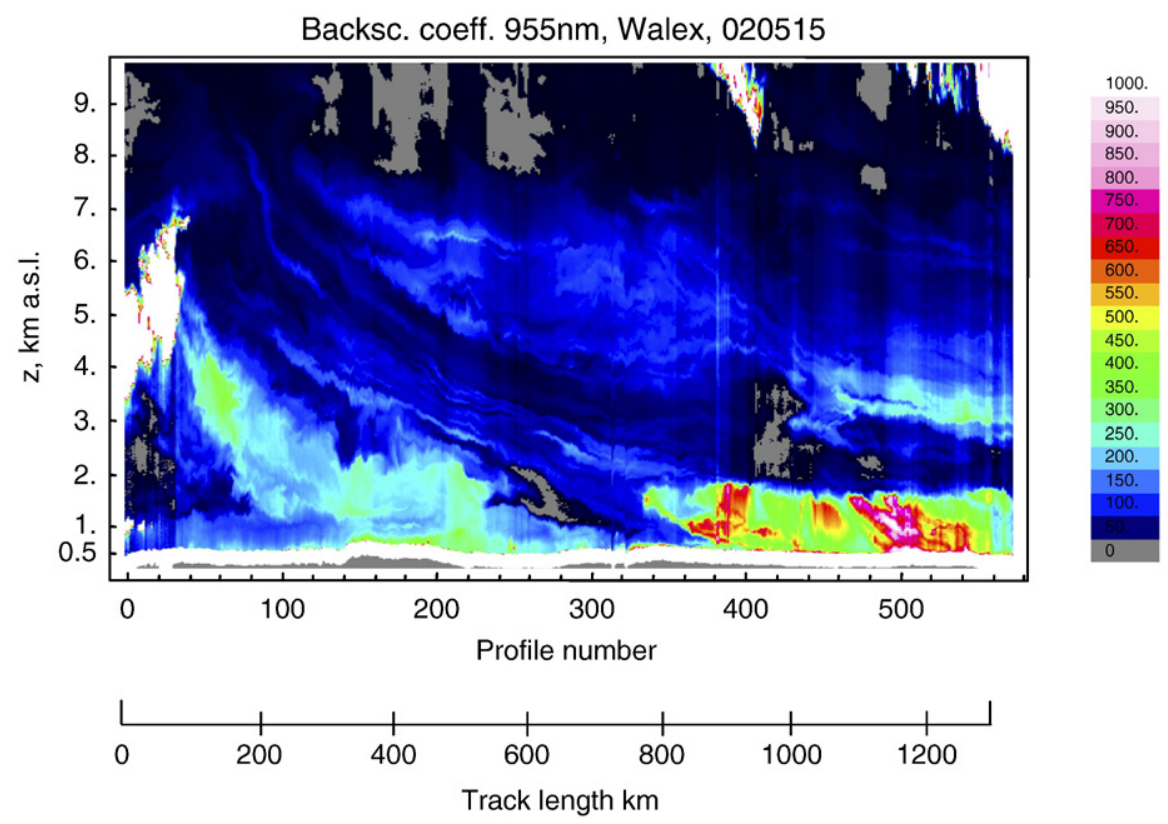

Fig. 2. Particle backscatter coefficient as $10^{-9} /(\mathrm{m} \mathrm{sr})$ measured with DLR-DIAL. 


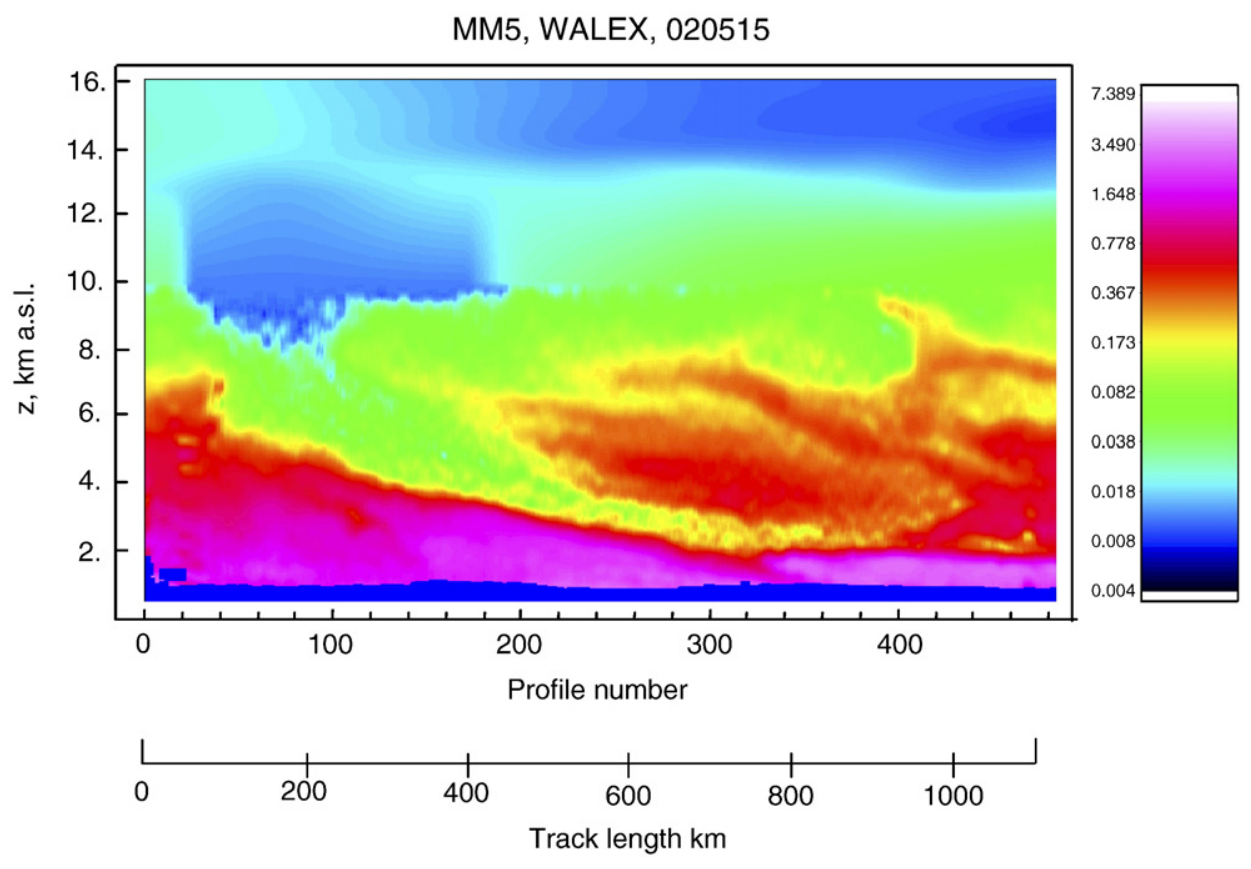

Fig. 3. Composite water vapour field as obtained through the merging of the DLR-DIAL and MM5 datasets (horizontal gliding average of 5 bins, and vertical gliding average of 21 bins).

DIAL and MM5 datasets, mixing ratio values in the 10-13 km region were re-determined considering the values obtained from the linear interpolation of DLR-DIAL mixing ratio at $10 \mathrm{~km}$ and MM5 mixing ratio at $13 \mathrm{~km}$. In order to reduce statistical fluctuations, data have been smoothed with a gliding average of 5 and 21 bins in the horizontal and vertical scale, respectively. Resulting horizontal and vertical resolution are better than 10 and $2 \mathrm{~km}$, respectively. The composite water vapour field after smoothing is illustrated in Fig. 3.

An adaptive approach was considered to determine the particle backscatter profile from DLR off-line signals in cloudy conditions. The lidar ratio value (ratio of particle extinction over backscattering coefficient) inside the cloud was iteratively varied to produce particle backscatter profiles below clouds compatible with those determined in close-by cloud-free profiles. This approach assumes horizontal homogeneity of the aerosol layer below the clouds, and no coupling between the clouds and the aerosol layer beneath. Fig. 4 illustrates the variability of lidar ratio along the considered $1100 \mathrm{~km}$ length segment, as determined through the adaptive approach mentioned above, and the corresponding values of the optical thickness of aerosol and clouds. The step behaviour of the lidar ratio is to be attributed to the transition between regions with different aerosol properties. Specifically, the change from 32 to $52 \mathrm{sr}$ found around profile 430 is associated with the transition from lower to higher aerosol loadings, which is clearly observed in Fig. 2 both in the boundary layer and the free troposphere.

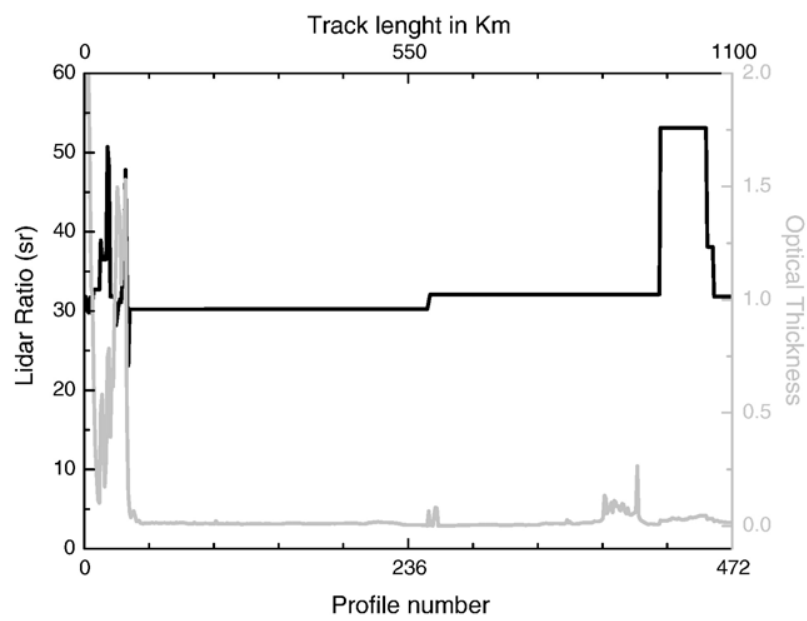

Fig. 4. Variability of lidar ratio and optical thickness of aerosol and clouds along the $1100 \mathrm{~km}$ length segment of the WALEX experiment. 


\subsection{Determination of the synthetic DIAL signals}

The dataset discussed in Section 2.4 is ingested into the end-to-end simulator in order to generate the synthetic lidar signals to be used for the analysis. Two different output products are generated by the end-to-end simulator from the WALEX dataset. First output is the 2D (time-height) reconstruction of both the particle backscatter and the water vapour fields as measured by the space-DIAL system, while the second output is the corresponding 2D-plot of random error and bias. Two different ensembles of synthetic signals must be generated for these two different efforts. In fact, in order to obtain the 2D water vapour/particle backscatter reconstructions to be compared with the original DLR-DIAL measurements, the number of input and output water vapour/backscatter profiles need to be identical and the horizontal spacing between adjacent profiles must be the same. On the other hand, for the purpose of determining the 2D-plot of bias and random error, a smaller horizontal step is sufficient. A horizontal step of $25 \mathrm{~km}$ was considered for this goal. More details on the two distinct datasets are provided in the following sections.

\subsubsection{Synthetic signals for the $2 D$ reconstruction of the particle backscatter and water vapour fields}

390 groups of synthetic signals, each one including four quadruplets of signals $P_{\lambda}^{k, 25 \mathrm{~km}}(z), P_{\lambda}^{k, 100 \mathrm{~km}}(z), P_{\lambda}^{k, 150 \mathrm{~km}}(z)$ and $P_{\lambda}^{k, 200 \mathrm{~km}}(z)$, with $k=1, \ldots, 390$, are considered to cover the $1100 \mathrm{~km}$ length segment considered in this study. These are obtained from the original 475 profiles of water vapour mixing ratio, $x_{H 2 O, i}(z)$, and particle backscattering coefficient, $\beta_{p a r, i}$ $(z)$, specified in Section 2.4 (Figs. 2 and 3). The vertical profiles of $x_{\mathrm{H}_{2} \mathrm{O}, \mathrm{i}}(z)$ and $\beta_{\text {par, } i}(z)$, together with the temperature and pressure profiles provided by the nearest available radiosonde (below $10 \mathrm{~km}$ ) and the temperature and pressure information provided by MM5 analysis (above $10 \mathrm{~km}$ ), are ingested into the simulator to generate the corresponding quadruplets of single-shot off-weak-medium-strong-line synthetic signals $P_{\text {off, } i}(z), P_{w k, i}(z), P_{\text {med, } i}(z)$, and $P_{s t r, i}(z)$, with $i=1, \ldots, 475$, each with a profile separation of $2.33 \mathrm{~km}$. As the number of laser shots fired by the laser along the $2.33 \mathrm{~km}$ length segment at each

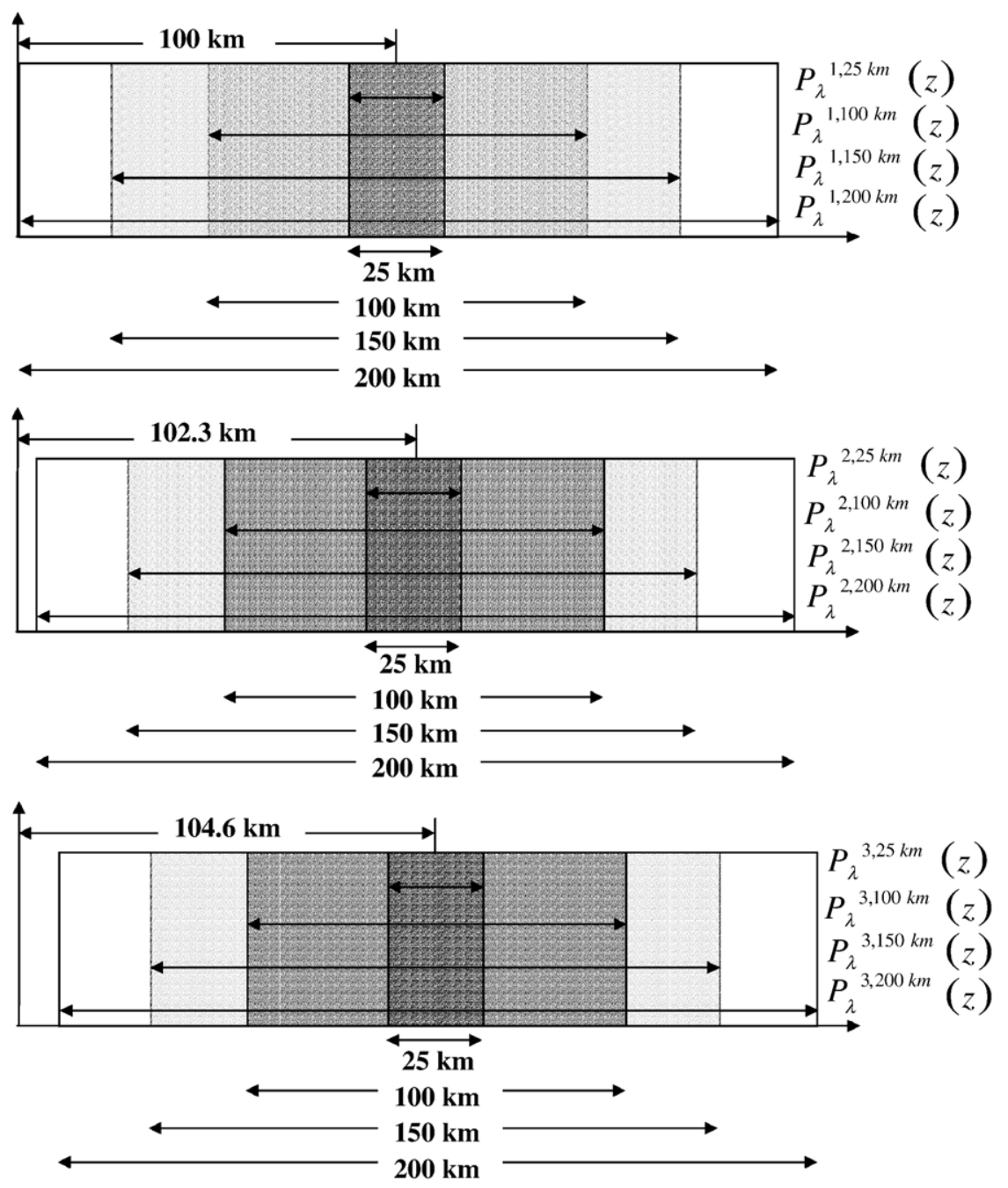

Fig. 5. Horizontal integration strategy used to generate the synthetic lidar signals for the $2 \mathrm{D}$ reconstruction of the particle backscatter and water vapour fields. 
wavelength is approximately 8 , each of the signals above is multiplied by a factor of 8 . Thus, the 390 distinct groups of synthetic signals needed for this study are determined through the expressions:

$$
\begin{gathered}
P_{\lambda}^{k, 25 \mathrm{~km}}(z)=8 \sum_{i=38+(k-1)}^{48+(k-1)} P_{\lambda, i}(z) \text { with } k=1, \ldots, 390, \text { and } i=1, \ldots, 475 \\
P_{\lambda}^{k, 100 \mathrm{~km}}(z)=8 \sum_{i=22+(k-1)}^{64+(k-1)} P_{\lambda, i}(z) \\
P_{\lambda}^{k, 150 \mathrm{~km}}(z)=8 \sum_{i=11+(k-1)}^{75+(k-1)} P_{\lambda, i}(z) \\
P_{\lambda}^{k, 200 \mathrm{~km}}(z)=8 \sum_{i=0+(k-1)}^{86+(k-1)} P_{\lambda, i}(z)
\end{gathered}
$$

Fig. 5 describes the averaging strategy considered, as applied to the first three groups of synthetic signals.

\subsubsection{Synthetic signals to determine the 2D-plot of bias and random error}

For the purpose of determining the 2D-plot of bias and random error, high horizontal resolution $(2.33 \mathrm{~km})$ is not needed and a larger horizontal step can be considered. A horizontal step of $25 \mathrm{~km}$ is used for this effort. This drastically reduces the
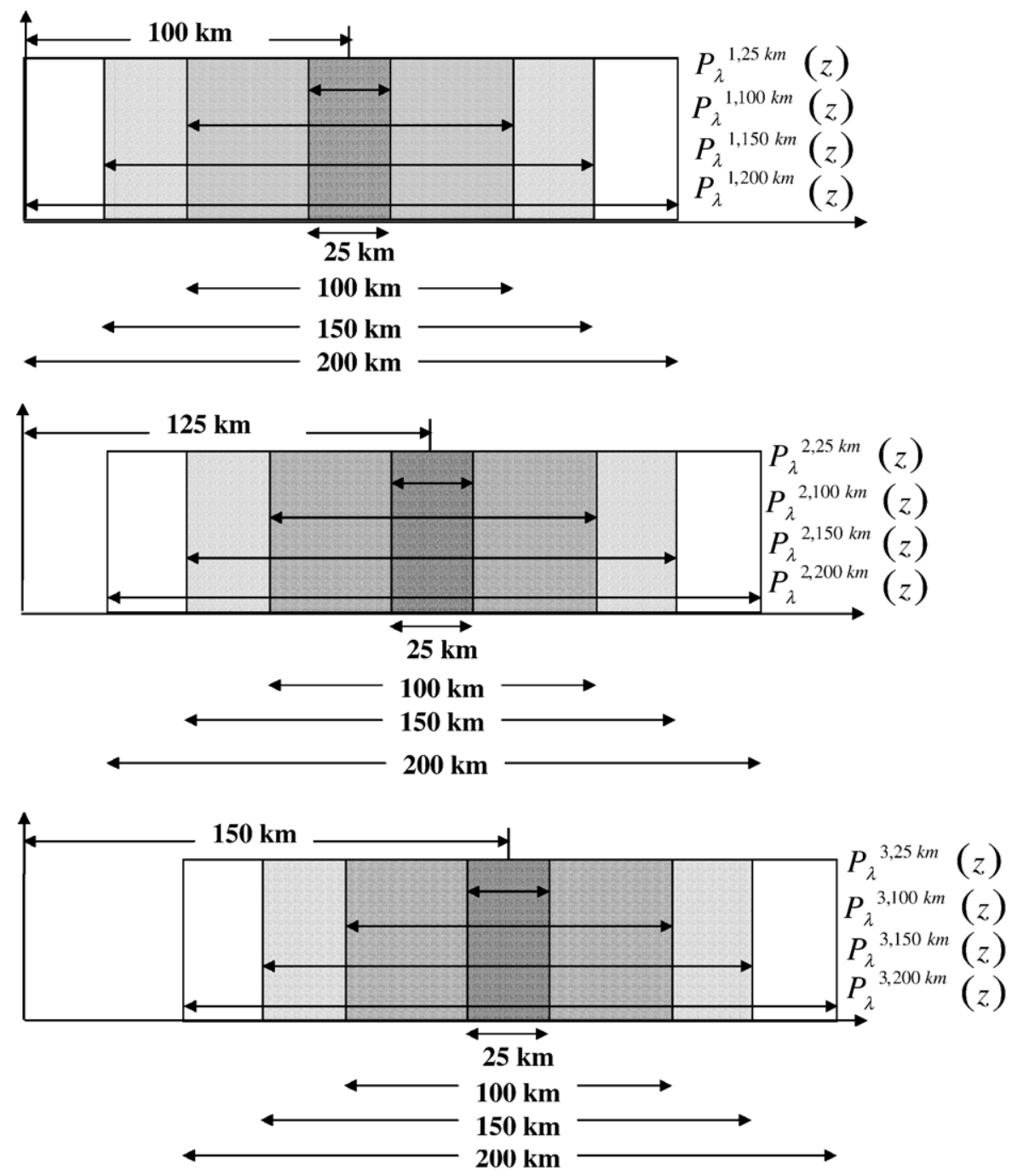

Fig. 6. Horizontal integration strategy used to generate the synthetic lidar signals for the determination of the 2D-plot of bias and random error. 
computation time needed for the determination of the 2D cross-section of bias and random error. We have to recall at this point that, in order to determine the vertical profile of bias and random error for each atmospheric scenario, an ensemble of 1000 synthetic DIAL signals and the corresponding water vapour retrievals are needed. Thus, in order to determine the 2D-plot of bias and random error with high horizontal resolution $(2.33 \mathrm{~km})$, the forward simulation of $6,240,000$ synthetic lidar signals $(1000 \times 390 \times 4 \times 4)$ and an equal number of retrieval operations would be necessary.

Considering instead a horizontal step of $25 \mathrm{~km}$, the $1100 \mathrm{~km}$ length segment is covered with 36 profiles. Thus, 36 groups of synthetic signals are considered here, each one including four quadruplets of signals $P_{\lambda}^{k, 25 \mathrm{~km}}(z), P_{\lambda}^{k, 100 \mathrm{~km}}(z), P_{\lambda}^{k, 150 \mathrm{~km}}(z)$, and $P_{\lambda}^{k, 200 \mathrm{~km}}(z)$, this reducing the number of forward simulations and retrievals to $576,000(1000 \times 36 \times 4 \times 4)$. Fig. 6 shows the considered horizontal integration strategy.

The 36 distinct groups of synthetic signals to be used for this effort are determined through the expressions:

$$
\begin{aligned}
& P_{\lambda}^{k, 25 \mathrm{~km}}(z)=8 \sum_{i=38+11(k-1)}^{48+11(k-1)} P_{\lambda, i}(z) \text { with } k=1, \ldots, 36, \text { and } i=1, \ldots, 475 \\
& P_{\lambda}^{k, 100 \mathrm{~km}}(z)=8 \sum_{i=22+11(k-1)}^{64+11(k-1)} P_{\lambda, i}(z) \\
& P_{\lambda}^{k, 150 \mathrm{~km}}(z)=8 \sum_{i=11+11(k-1)}^{75+11(k-1)} P_{\lambda, i}(z) \\
& P_{\lambda}^{k, 200 \mathrm{~km}}(z)=8 \sum_{i=0+11(k-1)}^{86+11(k-1)} P_{\lambda, i}(z)
\end{aligned}
$$

\section{Results}

\subsection{Reconstruction of the particle backscatter and the water vapour mixing ratio fields}

Fig. 7 shows the end-to-end simulator reconstruction of the WALEX particle backscatter field as measured by the spaceDIAL system. Particle backscatter is obtained from the off-line signals based on the application of the analytical inversion approach illustrated in Di Girolamo et al. (2004).

No specific observational requirement has been defined for particle backscatter measurements. Due to the relatively high signal-to-noise ratio level of the off-line signals, present particle backscatter retrievals are determined based on a signal horizontal integration over only $25 \mathrm{~km}$, i.e. solely the $P_{\lambda_{\text {off }}}{ }^{k, 25} \mathrm{~km}(z)$ signals are considered and used for the retrieval.

Fig. 7 closely reproduces the original DLR-DIAL particle backscatter field (Fig. 2), with aerosol and cloud features properly captured. Even thin $(\sim 1 \mathrm{~km}$ thick) aerosol filaments are revealed by space-DIAL system. However, some features are lost below the cirrus clouds around profile 400. The presence of the vertical stripes in the retrieved field is a typical effect arising from the use of a non-self-calibrating technique, as is the one used to determine particle backscatter; the effect is

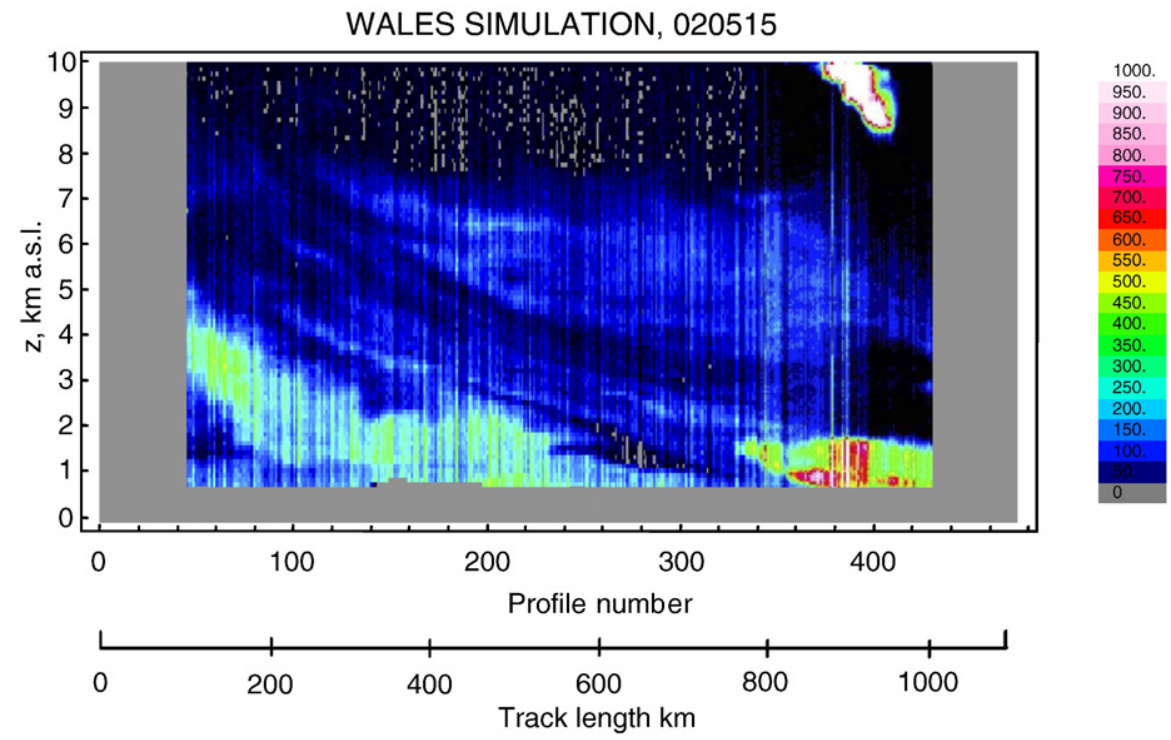

Fig. 7. Space DIAL reconstruction of the WALEX particle backscatter field. 


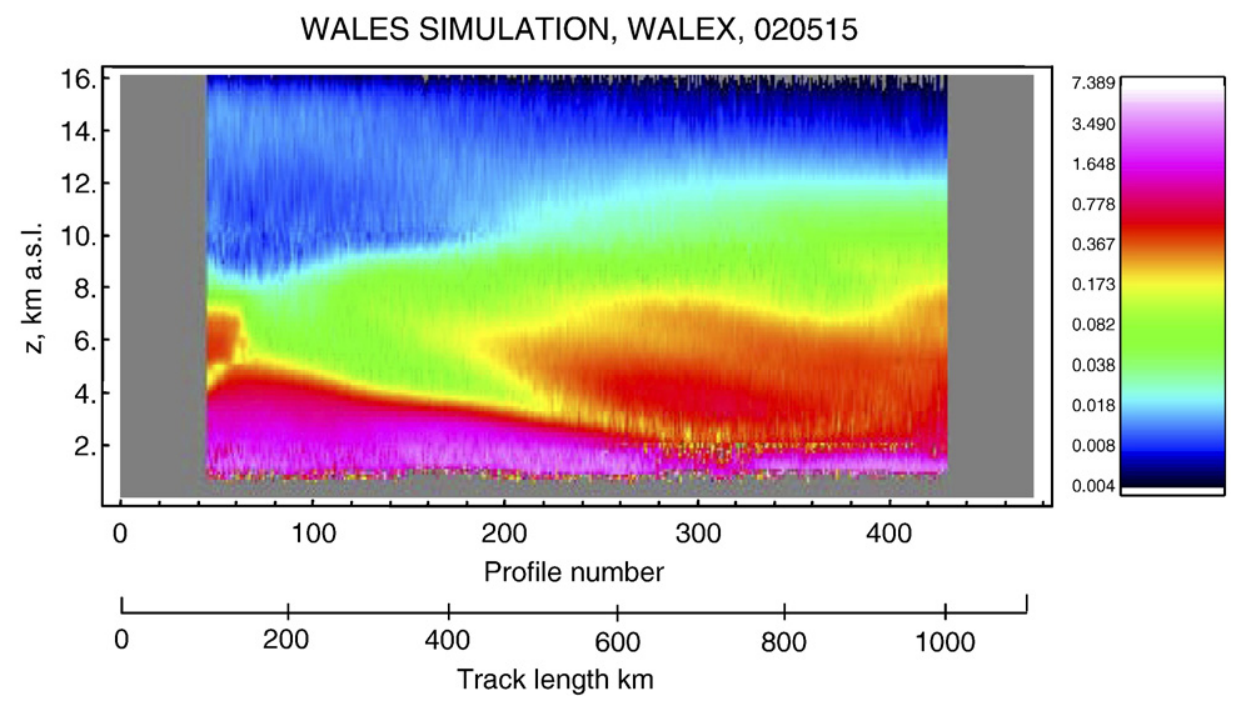

Fig. 8. Space DIAL reconstruction of the WALEX humidity field (horizontal resolution of $25 \mathrm{~km}$ up to the PBL top, of $100 \mathrm{up}$ to $5 \mathrm{~km}$, of $150 \mathrm{up}$ to $10 \mathrm{~km}$ and of 200 above $10 \mathrm{~km}$ ).

associated with the fluctuations of the signal $P_{\lambda_{\text {off }}} k, 25 \mathrm{~km}(z)$ in the proximity of the normalization height, usually in the lower stratospheric region. It is not the subject of this paper to calibrate the lidar signal returns, as this is not necessary for DIAL retrievals.

Fig. 8 shows the reconstructed humidity field. This reconstruction is based on the height-dependent horizontal and vertical resolutions reported in Table 2 and is obtained from the synthetic DIAL signals $P_{\lambda}^{k, 25 \mathrm{~km}}(z), P_{\lambda}^{k, 100 \mathrm{~km}}(z), P_{\lambda}^{k, 150 \mathrm{~km}}(z)$ and $P_{\lambda}^{k, 200 \mathrm{~km}}(z)$ discussed in Section 2.5.1. This field extends down to $1 \mathrm{~km}$ above surface, the lower reachable level being limited by the vertical resolution of the data ( $1 \mathrm{~km}$ in the PBL). In case of real measured data, the use of the surface reflection would allow to extend the water vapour measurements closer to the surface (100-200 m). In fact, the DIAL algorithm can also be applied to the lidar signals close to the surface and to the surface echoes. This permits a water vapour estimate closer to the surface, as illustrated by Browell (1995). However, more studies have to be performed to verify whether this works from space, as a very high spatial correlation between the surface reflectivities between the online and offline shots is essential. The reconstructed water vapour field is characterized by small statistical fluctuations, as a result of the reasonably high signalto-noise ratio level of the considered lidar signals. However, some specific features present in the original DLR-DIAL humidity map are not properly captured (for example the "comma" shaped feature present below the cirrus clouds around profile 400). An artificial feature in the initial portion of the reconstructed humidity field (from approximately profile 43 through 63) is present between 5 and $7 \mathrm{~km}$; this feature is associated with the presence in profiles $0-43$ of thick clouds in this same altitude interval.

Fig. 9 shows the reconstructed humidity field based on the use of only the synthetic DIAL signals $P_{\lambda}^{k, 25} \mathrm{~km}(z)$. The

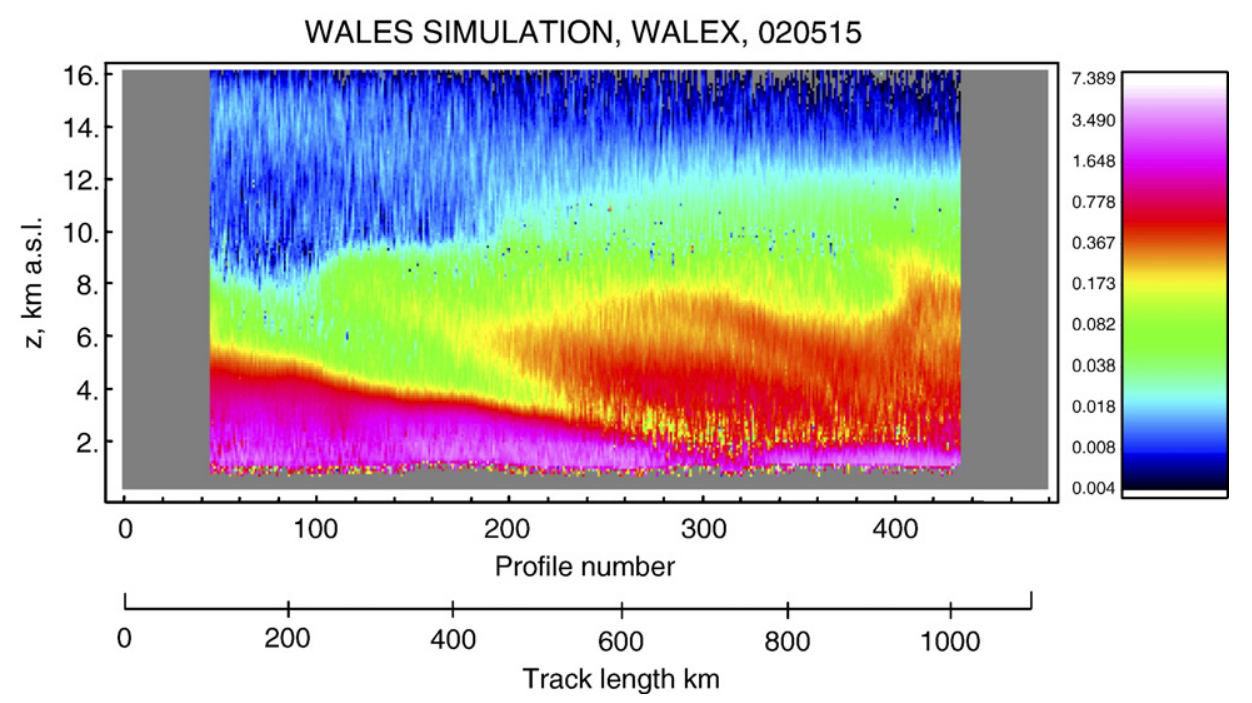

Fig. 9. Space DIAL reconstruction of the WALEX humidity field (horizontal resolution $=25 \mathrm{~km}$ ). 
reconstruction at $25 \mathrm{~km}$ horizontal resolution, while characterized by larger statistical fluctuations than the previous, seems to be able to capture all relevant features associated with water vapour variability. This reconstruction, for example, reproduces the "comma" shaped feature present in the humidity field in the proximity of the cirrus clouds (around profile 400), as well as dry air filaments intruded from the UTLS region into the middle and lower troposphere. The artificial feature that was present between 5 and $7 \mathrm{~km}$ in Fig. 8 (profiles 43-63) results to be disappeared in Fig. 9, as a result of the smaller horizontal integration length ( 25 instead of $150 \mathrm{~km}$ ) used in this latter figure for the same altitude range. The use of a smaller horizontal integration prevents from including signals affected by the presence of thick clouds (profiles 0-43) among those used for reconstructing the water vapour mixing ratio field and thus minimizes systematic errors associated with the application of the Doppler broadening correction algorithm.

\subsection{Two-dimensional plot of random error and BIAS}

Fig. 10 illustrates the 2D plot of bias (upper portion) and random error (lower portion). The random error is less than $20 \%$ up to $16 \mathrm{~km}$, with relatively higher values (up to $30 \%$ ) occasionally observed around $2 \mathrm{~km}$ at the lower edge of the stratospheric intruded dry air tongue. The maximum systematic error is less than $5 \%$ up to $16 \mathrm{~km}$, except in the presence of thick cirrus and mid level clouds and occasionally inside the dry stratospheric intrusion (left portion of figure). It is to be pointed out that presence of clouds has a significant effect on bias, but not on random error. The clouds encountered along the flight track are mid-level clouds (left portion of the flight segment, profiles 0-43) and cirrus clouds (right portion of the flight segment, profiles 320-410), both formations characterized by large optical thicknesses ( 2 and 0.3 , respectively, with aerosol scattering ratio values up to 1000 and 500) and sharp edges with large scattering gradients. The Doppler broadening effect associated with these clouds cannot be completely corrected for without a priori knowledge of the lidar ratio profile within the cloud region. A height-independent value for the lidar ratio was considered for each quadruplet of signals, leading to a residual bias error after correction of $\sim 5 \%$ in the cloud region, with slightly larger values at the cloud edges. Some improvements of the retrievals at the cloud edges are obtained based on a more careful selection of the lidar ratio profile; a specific sensitivity analyses of the systematic error dependence on lidar ratio is reported in Di Girolamo et al. (2004).

Additionally, in the present dataset cirrus clouds are found in the altitude region $9-11 \mathrm{~km}$, this being a region characterized by significant difficulties in the application of the DIAL retrieval procedure (Di Girolamo et al., 2004). In fact, lidar signals in this altitude interval are low and characterized by small signal-tonoise ratio levels. This is the region where the transition from the strong to the medium pair takes place in the application of the DIAL equation, and here non-negligible effects on bias are produced. A similar situation is present in the altitude region 4$6 \mathrm{~km}$, in the region of mid level clouds, where the transition from the medium to the weak pair takes place. The dashed area in Fig. 10 represent the cloudy areas where bias is slightly in
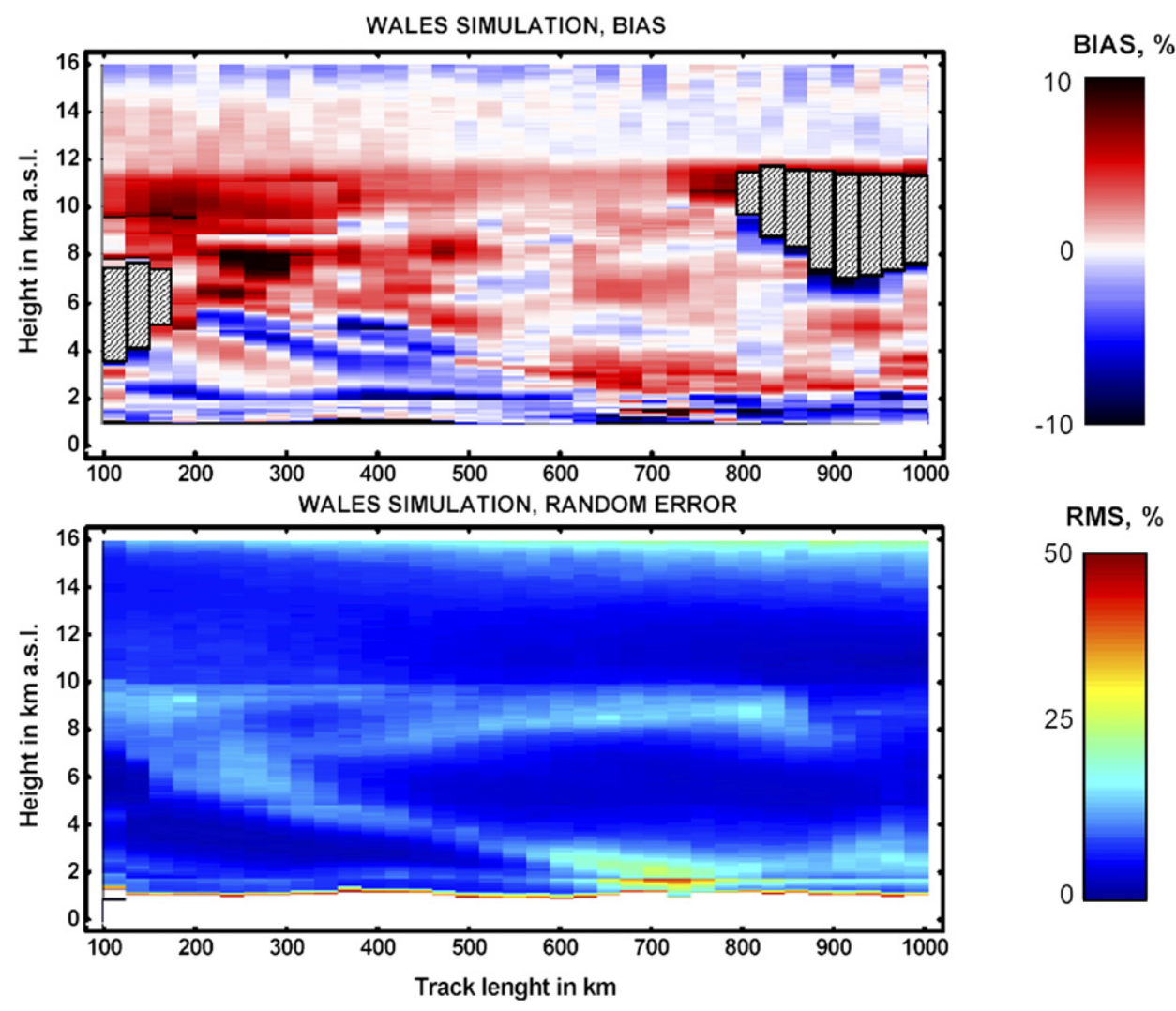

Fig. 10. 2D plot of the bias (upper portion) and random error (lower portion). 
excess of $10 \%$, as a result of the small signal-to-noise ratios of signals and the residual Doppler broadening effect. While bias is large inside clouds, it is found to be small $( \pm 3 \%)$ below clouds.

With respect to random errors, in the regions of optically thin clouds, the SNR increases resulting in a random error that is smaller than in clear air (lower portion of Fig. 10). With respect to bias, measurements in optically thin clouds are very accurate if cloud edges can be omitted in the retrieval (all range gates in the cloud). As the bias at cloud edges increases due to limited Rayleigh-Doppler correction, these regions should be handled with care and excluded when deriving water vapour climatologies.

The MM5 water vapour number density values considered above $10 \mathrm{~km}$ are up to a factor of 3-4 larger than the corresponding climatological values. Climatological values of water vapour number density at mid-latitude and tropical regions in the height interval $14-16 \mathrm{~km}$ are in the range $1.2-$ $9.0 \times 10^{19} \mathrm{~m}^{-3}$, compared to $5.0-12.0 \times 10^{19} \mathrm{~m}^{-3}$ which is found in the present MM 5 dataset. These very high upper tropospheric humidity levels, which are considered in order to reproduce the extreme conditions occasionally found in association with warm conveyor belts (Stohl, 2001; Wernli \& Bourqui, 2002), are partially responsible for the large bias values (up to $10-15 \%$ ) found in the region of clouds and for those occasionally found in the UTLS region (8-10\%).

Additional simulations were performed considering an alternative input humidity field, i.e. using the DLR-DIAL water vapour data up to $10 \mathrm{~km}$ and data from a reference atmospheric model (mid-latitude summer) above $10 \mathrm{~km}$. Fig. 11 illustrates the bias/random error 2D plot as obtained from the use of this alternative input humidity field. The mean bias up to $16 \mathrm{~km}$ is $-0.7 \%$, while it is $-1.0 \%$ up to $12 \mathrm{~km}$. For this case, bias is found to not exceed $\pm 5 \%$ also in the region of clouds, in the UTLS region and inside the dry stratospheric intrusion. The lower bias values in Fig. 11 with respect to those in Fig. 10 are the result of considering a drier UTLS than MM5. This leads to a lower attenuation of the lidar signals throughout the atmosphere and consequently to larger signal-to-noise levels in the region of clouds and within the dry stratospheric intrusion. As we mentioned above, clouds and dry stratospheric intrusion are both located in the transition regions between different wavelength pairs where signal-to-noise level is small; thus, small residual effects in terms of the bias are associated with the application of the non linear operators present in the DIAL equation and the Doppler broadening effect. However, this effect is strongly reduced in the present measurement scenario, characterized by a drier UTLS region, as a result of the larger signal-to-noise levels of signals. Concerning the sign of the bias, it is to be noticed that slightly positive values are observed in the dry regions (upper troposphere and dry intrusion), while slightly negative values are observed in the regions of clouds and in wet regions (lower and middle troposphere), as well as in the 11$14 \mathrm{~km}$ region (which is a region primarily covered by the strongmedium wavelength pair).

The mean random error is $13.2 \%$ up to $16 \mathrm{~km}$, while it is $7.6 \%$ up to $12 \mathrm{~km}$. It is noteworthy the appearance with respect
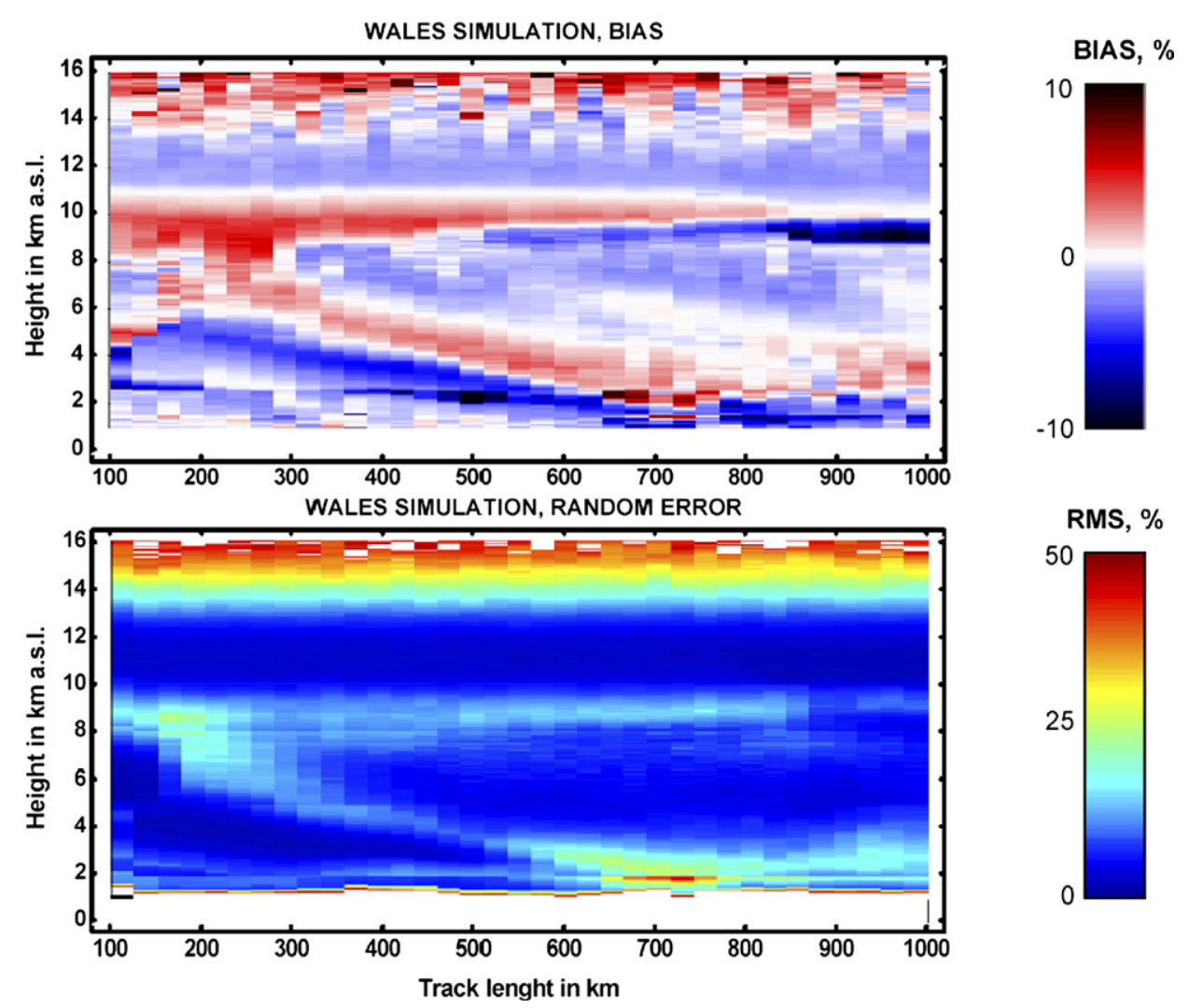

RMS, \%

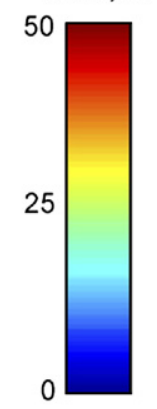

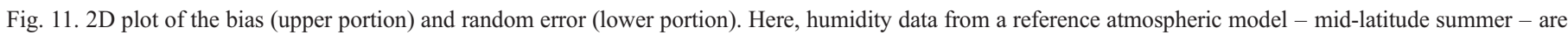
used as input above $10 \mathrm{~km}$. 


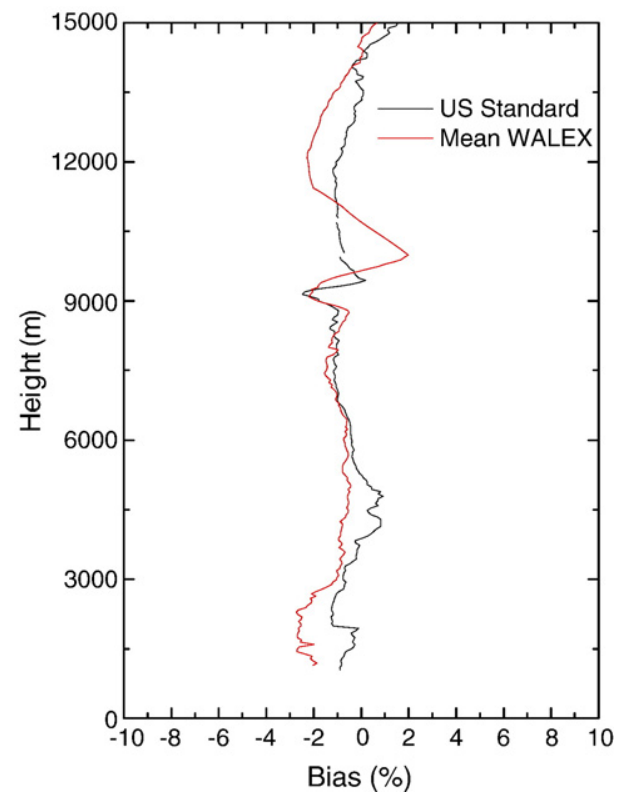

Fig. 12. Mean bias profile (red line); US Standard atmosphere profile is also reported for comparison (black line). Results in this figure are based on the altitude dependent horizontal and vertical resolutions specified in the requirement Table 2. (For interpretation of the references to colour in this figure legend, the reader is referred to the web version of this article.)

to the DLR-DIAL+MM5 scenario of a slight random error increase in the dry intrusion region (up to $\sim 20 \%$ ), this increase being determined by the higher sky background level associated with the smaller water vapour absorption, and thus the smaller water vapour filtering effect in the UTLS region. It is also to be noticed that, relatively high random error values (up to $30 \%$ ) are

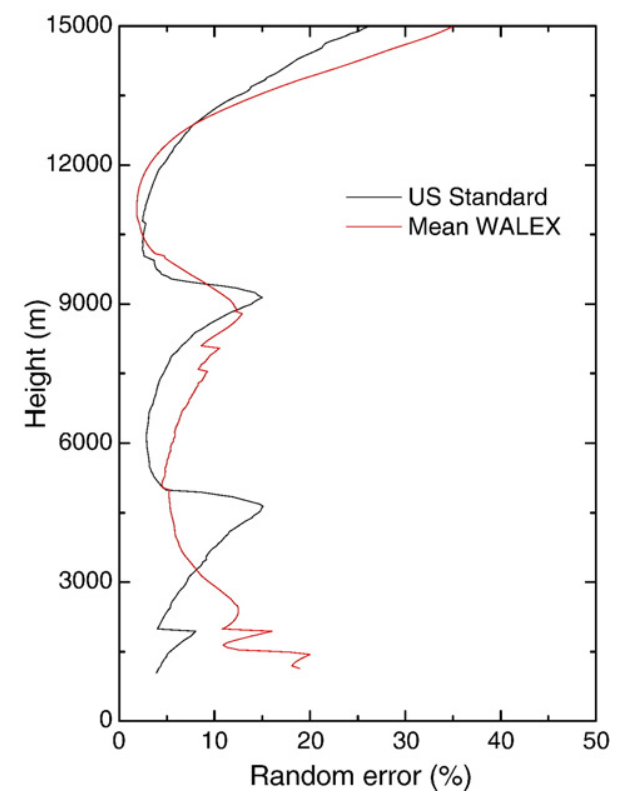

Fig. 13. Mean random error profile (red line); US Standard atmosphere profile is also reported for comparison (black line). Results in this figure are based on the altitude dependent horizontal and vertical resolutions specified in the requirement Table 2. (For interpretation of the references to colour in this figure legend, the reader is referred to the web version of this article.) observed around $2 \mathrm{~km}$ at the lower edge of the stratospheric intruded dry air tongue.

Figs. 12 and 13 show the mean profiles of bias and random error as obtained by averaging the 36 profiles above. Corresponding profiles for the US Standard atmosphere (taken from Di Girolamo et al., 2004) are also reported in the figures for comparison. Profiles of bias and random error for the US Standard atmosphere were determined through the application of the procedure discussed in Section 2.3 to the synthetic signals obtained from the US Standard atmosphere profiles of pressure, temperature and water vapour. Values of the mean bias profile are very close to those found for the US Standard atmosphere. A peak value of 2.7 is found at $2.3 \mathrm{~km}$ in coincidence with the top of the PBL top. Mean bias is smaller than $3 \%$ up to $16 \mathrm{~km}$. While random error values for the US Standard atmosphere are found to be as large as $15 \%$ up to $\sim 13.5 \mathrm{~km}$, values for the mean WALEX profile in the same height interval are always smaller than $12 \%$, except for a very limited region at the top of the PBL. Furthermore, the relative maximum around $4.5 \mathrm{~km}$ present in the US Standard atmosphere random error profile is not found in the mean WALEX profile, this absence being most probably to be attributed to the large variability of random error in the height interval 3-6 km for those profiles considered in the mean and the consequent smoothing out of the distinct structures present in the different profiles.

Figs. 14 and 15 show the histograms illustrating the distribution of random error and bias up to $16 \mathrm{~km}$, as well as their distribution as a function of altitude, considering $2 \mathrm{~km}$ steps. In these figures the number of occurrences, expressed in percentage, are reported considering steps of $2 \% .29 \%$ of the random error values are smaller than $4 \%, 64 \%$ of the random error values are smaller than $10 \%$, while $85 \%$ are smaller than $20 \%$. Most of the random error values smaller than $2 \%$ are associated with data points within the lower $2 \mathrm{~km}$. For what concerns the bias, it is to be noticed that $85 \%$ of the data points are characterized by values within $\pm 4 \%$, while $91 \%$ are within $\pm 6 \%$. Wider distributions are found in the altitude regions 8 -

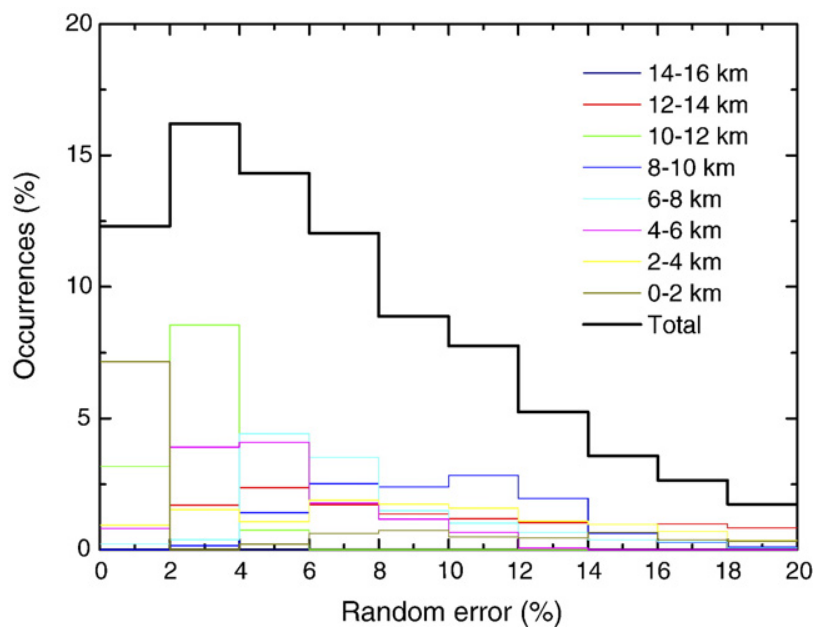

Fig. 14. Histogram of the random error percentage distribution, using steps of $2 \%$. Total values up to $16 \mathrm{~km}$, as well as values vs. altitude, considering $2 \mathrm{~km}$ steps, are reported. 


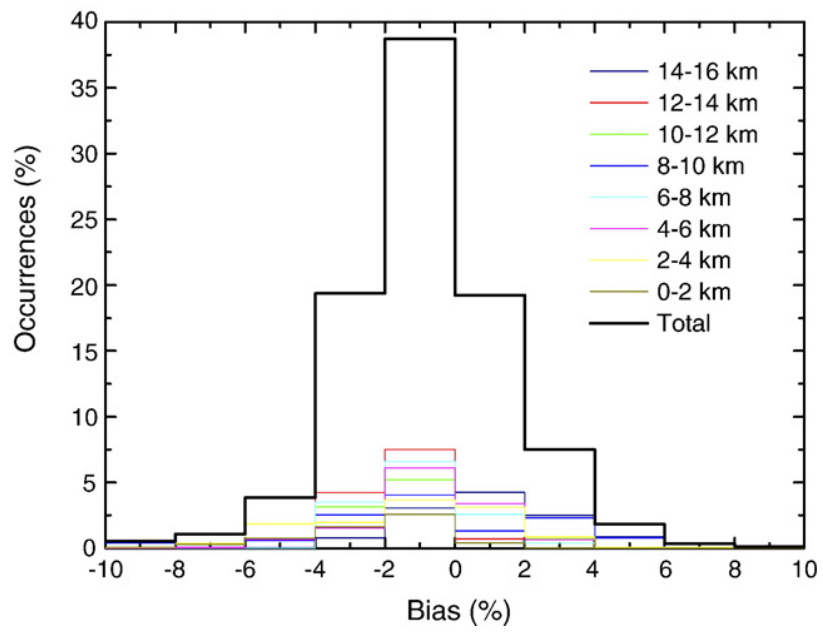

Fig. 15. Same as Fig. 14, but for bias.

$10 \mathrm{~km}$ and $14-16 \mathrm{~km}$, these being regions characterized by low signal-to-noise ratios for the medium and strong wavelength signals, respectively.

\section{Conclusions}

An end-to-end model has been used to assess the performances of a satellite water vapour DIAL system, such as WALES, which was one of the experiments considered by the European Space Agency for selection as Earth Explorer Core mission in the frame of the Earth Observation Envelope Programme 2 (EOEP2). More recently the model was also used for assessing the performances of the space mission SPACE WAVES, proposed in the frame of the EOEP3. In this study, as input for the simulator, real atmospheric measurements carried out by the DLR Falcon water vapour DIAL system during the WALEX experiment have been considered. The use of this dataset allowed for estimating the performances of a satellite water vapour DIAL system with the specifications of WALES in variable atmospheric conditions and for determining the effects on system performances associated with atmospheric inhomogeneities and variable cloud scenes.

UTLS water vapour data from both a mesoscale MM5 model and a reference atmospheric model - mid-latitude summer beyond the vertical range of the DLR-DIAL were merged with measurements below $10 \mathrm{~km}$ to derive a more complete data set for the simulator.

Results confirm the capability of satellite DIAL of reproducing the structure of the water vapour and particle backscatter fields with high resolution. Low bias and random error measurements are found to be possible even in the presence of clouds. Specifically, the systematic error obtained with the DLR-DIAL + MM5 dataset is found to never exceed 5\% up to $16 \mathrm{~km}$, except in the presence of thick cirrus and mid level clouds (up to 10-15\%) and occasionally inside the dry stratospheric intrusion. The systematic error obtained with the DLR-DIAL + climatology dataset is found to not exceed 5\% up to $16 \mathrm{~km}$ also in the region of clouds. The smaller bias associated with the DLR-DIAL+climatology dataset is the result of the drier UTLS and consequently the lower attenuation of the lidar signals and their higher signal-to-noise ratio. The random error is less than $20 \%$ up to $16 \mathrm{~km}$ for both datasets, except occasionally inside the lower portion of the dry stratospheric intrusion. Cirrus and mid-level clouds are found to increase the bias with respect to clear sky conditions, while their presence decreases the random error. It is one of the strengths of the DIAL methodology that these systematic and noise error profiles can be estimated for each retrieval, which is extremely powerful for future applications in climate and weather research.

Simulations in this paper clearly show that satellite DIAL systems based on state-of-the-art transmitter/receiver technology and exploiting the DIAL methodology in the near infrared can perform daytime atmospheric humidity measurements in clear-sky and cloudy conditions exceeding WMO threshold observational requirements for most NWP and climate research applications. Simulations clearly indicate that the space exploitation of the DIAL technique for water vapour measurements is very promising and they provide an advocacy for the inclusion of water vapour DIAL measurement capability in future space missions.

\section{References}

Ansmann, A. (1985). Errors in ground-based water-vapor DIAL measurements due to Doppler-broadened Rayleigh backscattering. Applied Optics, 24, 3476-3480

Behrendt, A., Wulfmeyer, V., Di Girolamo, P., Kiemle, C., Bauer, H. -S., Schaberl, T., et al. (2007). Intercomparison of water vapor data measured with lidar during IHOP_2002, Part 1: Airborne to ground-based lidar systems and comparisons with chilled-mirror hygrometer radiosondes. Journal of Atmospheric and Oceanic Technology, 24, 3-21.

Behrendt, A., Wulfmeyer, V., Kiemle, C., Ehret, G., Flamant, C., Schaberl, T., et al. (2007). Intercomparison of water vapor data measured with lidar during IHOP_2002, Part 2: Airborne to airborne systems. Journal of Atmospheric and Oceanic Technology, 24, 22-39.

Bengtsson, L., Hodges, K. I., \& Hagemann, S. (2004). Sensitivity of large-scale atmospheric analyses to humidity observations and its impact on the global water cycle and tropical and extratropical weather systems in ERA40. Tellus, 56 A, 202-217.

Bösenberg, J. (1998). Ground-based differential absorption lidar for water-vapor and temperature profiling. Applied Optics, 37, 3845-3860.

Browell, E. V. (1995). Airborne Lidar Measurements. Review of Laser Engineering, 23, 135-141.

Crook, N. A. (1996). Sensitivity of moist convection forced by boundary layer processes to low-level thermodynamic fields. Monthly Weather Review, 124, 1767-1785.

Di Girolamo, P., Behrendt, A., \& Wulfmeyer, V. (2006). Pure rotational Raman lidar measurements of atmospheric temperature and extinction from space: performance simulations. Applied Optics, 45(11), 2474-2494.

Di Girolamo, P., Summa, D., Wulfmeyer, V., Bauer, H., Bauer, S. H., \& Behrendt, A. (2004). Development of an end-to-end model to simulate the performances of a water vapour DIAL system in space. Final Report, ESA ESTEC Contract No. 16993/03/NL/FF (pp. 124).

Dudhia, J. (1993). A non-hydrostatic version of the Penn State - NCAR mesoscale model: Validation tests and simulation of an Atlantic cyclone and cold front. Monthly Weather Review, 121, 1493-1513.

Dudhia, J., Gill, D., Guo, Y. -R., Manning, K., \& Wang, W. (2001). PSU/NCAR mesoscale modeling system tutorial class notes and user's guide: MM5 modeling system version 3. Boulder, Colorado: Pennsylvania State University, National Center for Atmospheric Research (300 p.).

Ehret, G., Kiemle, C., Wirth, M., Stoffelen, A., Kummer, U., Schulte, H. R., et al. (2001). Evaluation of spaceborne differential absorption lidar for water vapour. Final Report, ESA Study 3654/00/NL/DC. 
Ehret, G., Wirth, M., Kiemle, C., Mayer, B., Gérard, E., Tan, D. G. H., et al. (2003). WALES (water vapour lidar experiment in space): a new space-borne active humidity profiler. 6th International Symposium on Tropospheric Profiling (pp. 438-440).

Ferrare, R. A., Browell, E. V., Ismail, S., Kooi, S. A., Brasseur, L. H., Brackett, V. G., et al. (2004). Characterization of upper-troposphere water vapor measurements during AFWEX using LASE. Journal of Atmospheric and Oceanic Technology, 21(12), 1790-1808.

Fiorani, L., \& Durieux, E. (2001). Comparison among error calculations in differential absorption lidar measurements. Optics and Laser Technology, 3, 371-377.

Flentje, H., Doernbrack, A., Ehret, G., Fix, A., Kiemle, C., Poberaj, G., et al. (2005). Water vapor heterogeneity related to tropopause folds over the North Atlantic revealed by airborne water vapor differential absorption lidar. Journal of Geophysical Research, 110(D03115). doi:10.1029/2004JD004957

Gérard, É., Tan, D. G. H., Garand, L., Wulfmeyer, V., Ehret, G., \& Di Girolamo, P. (2004). Major advances foreseen in humidity profiling from WALES (water vapour lidar experiment in space). Bulletin of the American Meteorological Society, 85(2), 237-251.

Hayden, K. L., Anlauf, K. G., Hoff, R. M., Strapp, J. W., Bottenheim, J. W., Wiebe, H. A., et al. (1997). The vertical chemical and meteorological structure of the boundary layer in the lower fraser valley during pacific ' 93 '. Atmospheric Environment, 31, 2089-2105.

Houghton, J. T., Ding, Y., Griggs, D. J., Noguer, M., van der Linden, P. J., Dai, X., Maskell, K., \& Johnson, C. A. (Eds.). (2001). Climate Change 2001: The Scientific Basis: Contribution of Working Group I to the Third Assessment Report of the Intergovernmental Panel on Climate Change : Cambridge University Press $881 \mathrm{pp}$.

Ismail, S., \& Browell, E. V. (1989). Airborne and spaceborne lidar measurements of water vapor profiles: a sensitivity analysis. Applied Optics, 28, 3603-3614.

Jedlovec, G. J. (1990). Precipitable water estimation from high-resolution split window radiance measurements. Journal of Applied Meteorology, 29, 851-865.

Kärcher, B., \& Haag, W. (2004). Factors controlling upper tropospheric relative humidity. Annales Geophysicae, 22, 705-715.

Marenco, A., Thouret, V., Nédélec, P., Smit, H., Helten, M., Kley, D., et al. (1998). Measurement of ozone and water vapor by Airbus in-service aircraft: The MOZAIC airborne program, An overview. Journal of Geophysical Research, 103, 25631-25642.

Poberaj, G., Fix, A., Assion, A., Wirth, M., Kiemle, C., \& Ehret, G. (2002). Airborne all-solid-state DIAL for water vapour measurements in the tropopause region: system description and assessment of accuracy. Applied Physics. B, 75, 165-172.
Schotland, R. M. (1974). Errors in the lidar measurement of atmospheric gases by differential absorption. Journal of Applied Meteorology, 13, 71-77.

Soden, B. J., \& Lanzante, J. R. (1996). An assessment of satellite and radiosonde climatologies of upper-tropospheric water vapor. Journal of Climate, 9, $1235-1250$.

Stohl, A. (2001). A 1-year Lagrangian "climatology" of airstreams in the Northern Hemisphere troposphere and lowermost stratosphere. Journal of Geophysical Research, 106, 7263-7279.

Tremberth, K. E., Dai, A., Rasmussen, R. M., \& Parson, D. B. (2004). The chancing character of precipitation. Bulletin of the American Meteorological Society, 84, 1205-1217.

Wang, J., Cole, H. L., Carlson, D. J., Miller, E. R., Beierle, K., Paukkunen, A., et al. (2002). Corrections of humidity measurement errors from the Vaisala RS80 radiosonde - application to TOGA COARE data. Journal of Atmospheric and Oceanic Technology, 19, 981-1002.

Weckwerth, T. M., Parsons, D. B., Koch, S. E., Moore, J. A., LeMone, M. A., Demoz, B. B., et al. (2004). An overview of the International $\mathrm{H}_{2} \mathrm{O}$ Project (IHOP_2002) and some preliminary highlights. Bulletin of the American Meteorological Society, 85, 253-277.

Weckwerth, T. M., Wulfmeyer, V., Wakimoto, R. M., Hardesty, R. M., Wilson, J. W., \& Banta, R. M. (1999). NCAR-NOAA lower-tropospheric water vapor workshop. Bulletin of the American Meteorological Society, 80, 2339-2357.

Wernli, H., \& Bourqui, M. (2002). A Lagrangian "1-year climatology" of (deep) cross-tropopause exchange in the extratropical Northern Hemisphere. Journal of Geophysical Research, 107(D2), 4021. doi:10.1029/2001JD000812

World Meteorological Organisation (WMO) (1998). Expert team, commission on basic systems (CBS), working group on satellites, third session. Final Report, Vol. 1. (pp. 73)Switzerland: Geneva.

Wulfmeyer, V., Bauer, H., Di Girolamo, P., \& Serio, C. (2005). Comparison of active and passive water vapor remote sensing from space: an analysis based on the simulated performance of IASI and space borne differential absorption lidar. Remote Sensing of Environment, 95, 211-230.

Wulfmeyer, V., Bauer, H. S., Grzeschik, M., Behrendt, A., Vandenberghe, F., Browell, E. V., et al. (2006). 4-dimensional variational assimilation of watervapor differential absorption lidar data: the first case study within IHOP_2002. Monthly Weather Review, 134, 209-230.

Wulfmeyer, V., \& Walther, C. (2001). Future performance of ground-based and airborne water-vapor differential absorption lidar. I. Overview and theory. Applied Optics, 40, 5304-5320.

Wulfmeyer, V., \& Walther, C. (2001). Future performance of ground-based and airborne water vapor differential absorption lidar. II: Simulations of the precision of a near-infrared, high-power system. Applied Optics, 40, 5321-5336. 